\title{
A Novel Framework for Evaluating and Improving Parameterized Subtropical Marine Boundary Layer Cloudiness
}

\author{
Mark Smalley, Kay Sušelu, Matthew Lebsock, And JoAo TeiXeira \\ Jet Propulsion Laboratory, California Institute of Technology, Pasadena, California
}

(Manuscript received 9 November 2018, in final form 10 June 2019)

\begin{abstract}
A single-column model (SCM) is used to simulate a variety of environmental conditions between Los Angeles, California, and Hawaii in order to identify physical elements of parameterizations that are required to reproduce the observed behavior of marine boundary layer (MBL) cloudiness. The SCM is composed of the JPL eddy-diffusivity/mass-flux (EDMF) mixing formulation and the RRTMG radiation model. Model forcings are provided by the Modern-Era Retrospective Analysis for Research and Applications, version 2 (MERRA2). Simulated low cloud cover (LCC), rain rate, albedo, and liquid water path are compared to collocated pixel-level observations from A-Train satellites. This framework ensures that the JPL EDMF is able to simulate a continuum of real-world conditions. First, the JPL EDMF is shown to reproduce the observed mean LCC as a function of lower-tropospheric stability. Joint probability distributions of lowertropospheric cloud fraction, height, and lower-tropospheric stability (LTS) show that the JPL EDMF improves upon its MERRA2 input but struggles to match the frequency of observed intermediate-range LCC. We then illustrate the physical roles of plume lateral entrainment and eddy-diffusivity mixing length in producing a realistic behavior of LCC as a function of LTS. In low-LTS conditions, LCC is mostly sensitive to the ability of convection to mix moist air out of the MBL. In high-LTS conditions, LCC is also sensitive to the turbulent mixing of free-tropospheric air into the MBL. In the intermediate LTS regime typical of stratocumulus-cumulus transition there is proportional sensitivity to both mixing mechanisms, emphasizing the utility of a combined eddy-diffusivity/mass-flux approach for representing mixing processes.
\end{abstract}

\section{Introduction}

Subtropical marine boundary layer (MBL) clouds exercise a large lever on the planetary radiative budget because of their strong shortwave and weak longwave radiative effects. General circulation models (GCM) have historically been deficient in their representation of subtropical marine boundary layer clouds and have typically had the problem of producing clouds that cover too little area but are also too bright (Karlsson et al. 2008; Nam et al. 2012). In addition, models are usually unable to capture the essential elements of the transition from subtropical stratocumulus to cumulus as the MBL is advected equatorward by the trade winds (Teixeira et al. 2011). The inability of models to represent the current subtropical MBL cloud conditions poses a question of whether they are able to realistically simulate MBL cloud response to global warming. In fact, the divergence in the model response of MBL clouds to

Corresponding author: Mark Smalley, mark.a.smalley@ jpl.nasa.gov anthropogenic warming is the dominant source of spread in climate sensitivity (Boucher et al. 2013).

Because subtropical MBL clouds are characterized by a subtle balance between several physical processes that include large-scale dynamics, convectiveand turbulent-scale mixing, radiation, microphysics, and aerosols (Wood 2012), their representation in GCMs requires an accurate description and coupling of these processes. The transition between subtropical stratocumulus to cumulus cloud regimes is particularly difficult, as it is governed by small changes of forcing (Sandu et al. 2010). Historically, the stratocumulus- and cumulusdominated boundary layer have been handled by separate parameterizations, which results in an abrupt and artificial transition between different regimes (e.g., Kubar et al. 2015). To move forward, unified representations of subgrid-scale mixing and convective processes have been developed (e.g., Lock et al. 2000; Golaz et al. 2002; Siebesma et al. 2007). Unified parameterizations have shown promise in their ability to improve representation of both stratocumulus and cumulus clouds without arbitrary transitions. For example, Kubar et al. (2015) find 
that the implementation of the Cloud Layers Unified By Binormals (CLUBB; Golaz et al. 2002) parameterization within the NCAR Community Atmosphere Model, version 5 (CAM5), improves the CAM5 simulated relationship of daily averaged low-cloud fraction and a metric of MBL inversion strength when compared to observed relationships derived from daily averaged MODIS low-cloud fraction. Recently, the eddy-diffusivity/mass-flux (EDMF) unified parameterization (Siebesma and Teixeira 2000) approach has been adopted at the Jet Propulsion Laboratory (JPL; Sušelj et al. 2012, 2013; 2019) in an effort to represent different boundary layer regimes within a common parameterization framework. The JPL EDMF in a singlecolumn model (SCM) has been shown to reproduce the marine stratocumulus and cumulus dominated boundary layers and transition between these regimes as simulated by large-eddy simulations (LES) (Sušelj et al. 2012, 2013, 2014, 2019).

Typically, GCM parameterizations are developed and validated in a SCM framework by comparison to results of LES for selected cases (e.g., Grabowski 1998; Cheinet and Teixeira 2003; Huang et al. 2013). Combining LES with observations from field campaigns is an attractive option, as the campaigns often involve intensive observations of atmospheric state from a variety of sources (e.g., surface, balloon, aircraft) and methods (remote and in situ observations) and are provided at high spatial and temporal resolution. LES also produce variables that are difficult to observe in nature (e.g., turbulent flux profiles), which are key parameterization variables. Field campaigns are also often focused on particular weather regimes so they provide characteristic profiles of atmospheres that serve as a common foundation for independent model development efforts.

However, the advantages of using field campaign data can also become weaknesses. Targeting a specific cloud type in a field campaign can introduce a selection bias in the resulting profiles of atmospheric state, as daily decisions are made about exactly where to fly the instrument-laden aircraft and which types of clouds to target. Also, the characteristic profiles for individual field campaigns are often idealized or smoothed as averages of a large number of observations (e.g., Nuijens and Stevens 2012; de Roode et al. 2016), eliminating important real-world weather fluctuations that need to be captured by parameterizations. Tuning model parameters for a few cases can bias the parameterization, leaving it unprepared to simulate conditions outside the narrow focus of studied cases.

Recent initiatives have addressed this issue of representativeness by running LES at heavily instrumented supersites for the purpose of comparison with SCMs (i.e., Neggers et al. 2012; Gustafson et al. 2017). However, these results are limited to their fixed locations. On the other hand, Earth-observing instruments aboard polar-orbiting satellites provide near-global observations of atmospheric state and could also be used to assess the performance of a cloud parameterization when the parameterization is initialized by profiles from global weather reanalyses. Comparisons of model output to observations of real-world atmospheres avoids the problem of overtraining the parameterization to particular weather regimes or averaged and idealized scenarios. The observations, often at the subcloud scale, provide estimates of the variability that is simulated by cloud parameterizations and can be upscaled to represent scene-averages at the grid scale. Although similar approaches have been suggested in the literature (e.g., Jakob 2003), the use of nativeresolution observations matched to simulations has yet to gain common use.

In this study, we first confirm that the latest version of the JPL EDMF parameterization (Sušelj et al. 2019) implemented within a SCM correctly reproduces mean lowlevel cloudiness when compared to spatially/temporally collocated observations from polar-orbiting instruments in the A-Train satellite constellation. We initialize and force the SCM with reanalyzed meteorological conditions from the NASA Modern-Era Retrospective Analysis for Research and Applications, version 2 (MERRA2; Gelaro et al. 2017), starting three hours before the satellite overpass until the time of satellite observations. The cloud observations are derived from the CALIPSO, CloudSat, MODIS, AMSR-E, and CERES missions (Stephens et al. 2018), which provide vertically resolved cloud, precipitation, and radiation properties at high resolution and sensitivity. We then investigate the sensitivity of the JPL EDMF in SCM mode to variations in parameters related to convection and turbulent mixing. In terms of model development and tuning, this calibration strategy permits parameters and model physics to be adjusted according to the aggregate of simulations containing real-world variability, therefore seeking to avoid tuning to specific weather and cloud regimes. This framework represents a relatively simple and inexpensive method of identifying key physical processes for simulating a transition between stratiform and shallow-convective boundary layers. Of course, this method is not without its own disadvantages. Of utmost importance are questions of the reliance on the weather reanalyses for the initial state and forcing and whether or not the parameterization is able to adjust and compensate for flawed forcing. These issues are considered throughout the body and summary of this document.

This paper is organized as follows. The JPL EDMF parameterization, which represents small-scale turbulence, 
subgrid-scale convective motions, condensation and cloud formation, warm rain microphysics, and radiative processes are outlined in section 2 . The single-column model, domain, and observational assessment frameworks are explained in section 3. Section 4 investigates the ability of the JPL EDMF parameterization to reproduce observed patterns of subtropical marine boundary layer cloudiness and section 5 provides a sensitivity analyses based on parameters related to mixing in the marine boundary layer. A summary is provided in section 6 .

\section{The JPL eddy-diffusivity/mass-flux parameterization}

The core of the JPL eddy-diffusivity/mass-flux parameterization (EDMF; Sušelj et al. 2019) is a unified turbulence and convection parameterization with prognostic equations for moist conserved variables (liquid/ ice water potential temperature and total water mixing ratio), subgrid variability of temperature and moisture, and horizontal winds. It couples subgrid-scale dynamics with condensation, cloud formation, and microphysical processes. A high-level description is provided here while a more complete formulation can be found in Sušelj et al. (2019) and differences from Sušelj et al. (2019) are explained here and in appendix A. The key idea of the EDMF approach is to separate the subgrid model domain into a convective area and a remaining nonconvective environment. An important difference between Sušelj et al. (2019) and the EDMF used here is the coupling of the parameterized mixing to warm microphysical processes and atmospheric radiation. The microphysical processes include the activation of $\mathrm{NaCl}$ and $\mathrm{SO}_{4}$ aerosols, the autoconversion of cloud water into rainwater, the accretion of cloud droplets by rain droplets, and the evaporation of cloud water. The activation of aerosols is based on the implementation of Abdul-Razzak and Ghan (2000) by Morrison and Gettelman (2008) and uses the bulk mass mixing ratios of $\mathrm{SO}_{4}$ and $\mathrm{NaCl}$ aerosols. Autoconversion and accretion are modeled as in Khairoutdinov and Kogan (2000) and the evaporation routine follows Grabowski (1998).

In the nonconvective environment, the effect of subgrid-scale motions is modeled with an eddydiffusivity approach using prognostic turbulent kinetic energy equations. This parameterization is coupled to a subgrid-scale cloud and condensation scheme based on an assumed normal probability density distribution (PDF) of the saturation excess (e.g., Cheinet and Teixeira 2003). In Sušelj et al. (2019), the variance of saturation excess was diagnosed, while in this version its prognostic equation is solved. For the nonconvective environment, the mean rates of microphysical processes are obtained by integration of those rates over the joint PDF of saturation excess and rainwater-mixing ratio. This approach closely follows Griffin and Larson (2016). Rain rate is computed with a steady-state equation.

Convection is represented by a mass-flux scheme with 10 steady-state surface-forced updrafts, which interact with the environment during their ascent via lateral entrainment. The entrainment rate is modeled with a stochastic parameterization that is a function of plume height. Convective updrafts are assumed to be dry at the surface and condense during the ascent if their total water mixing ratio exceeds the saturated water mixing ratio. The updrafts include the same three microphysical processes as does the nonconvective environment. An individual updraft is assumed to be associated with a uniform distribution of thermodynamic variables, therefore the computation of microphysical rates is straightforward. However, because convective microphysics and dynamics interact, the updraft equations are solved in iterative manner until the balance between these two processes is achieved.

Previous work (Sušelj et al. 2013) shows that the JPL EDMF is sensitive to the formulations of the lateral entrainment for convective plumes and the mixing length for the eddy-diffusivity parameterization. In section 5, we investigate the sensitivity of the JPL EDMF within a SCM to the formulation of these two distinct mixing processes. We slightly modify the formulations for plume entrainment and eddy-diffusivity mixing from Sušelj et al. (2019) (see appendix A for a detailed description). In short, we vary two model parameters that directly affect the magnitude of the two mixing processes. The first parameter $w_{0}$ [default value $126 \mathrm{~m} \mathrm{~s}^{-1 / 2}$; Eq. (A4)] is a combined length and velocity scale that controls the mass-flux mixing by modifying the plume lateral entrainment rate. Higher $w_{0}$ increases the frequency of entrainment events and therefore results in a higher mean lateral entrainment rate. A second parameter $A_{s}$ [default value $10^{-6} \mathrm{~s}^{-2}$; Eq. (A9)] controls the mixing length scale for the eddy-diffusivity formulation in statically stable layers. Its primary role is to limit mixing of free tropospheric air into the boundary layer without simultaneously limiting turbulent mixing within the boundary layer and thus we expect that its most important effect is the control of the growth of the stratocumulus boundary layers. The results that follow will explore the sensitivity of our results to variations in the two parameters $w_{0}$ and $A_{s}$ that primarily influence updraft plume lateral entrainment and stratiform cloud top entrainment, respectively.

Because radiation plays an important role in the development of low-level clouds, in particular for stratocumulus 
clouds, this version of the JPL EDMF is coupled to both the shortwave and longwave versions of the Rapid Radiative Transfer Model for GCMs (RRTMG; Iacono et al. 2000). For each radiative calculation, RRTMG assumes a subgrid distribution of cloudiness and computes the average of a 200-element Monte Carlo simulation (Pincus et al. 2003) of independent columns within the SCM domain, assuming maximumrandom cloud overlap.

\section{Methods}

\section{a. Single-column model setup}

In this study, the JPL EDMF is initialized with profiles of atmospheric state provided by the NASA ModernEra Retrospective Analysis for Research and Applications, version 2 (MERRA2; Gelaro et al. 2017). The MERRA2 data are provided at a spatial resolution of $0.5^{\circ}$ in latitude and $0.65^{\circ}$ in longitude and have various temporal resolutions, ranging from 1- to 3-hourly. Thermodynamic profiles are provided on 72 layers between the surface and $0.1 \mathrm{hPa}$. Appendix B provides a list of MERRA2 variables that provide initial conditions and time-dependent forcing to the SCM. Because the aerosol activation scheme used here (Abdul-Razzak and Ghan 2000; Morrison and Gettelman 2008) acts on bulk aerosol mass mixing ratios for each of $\mathrm{NaCl}$ and $\mathrm{SO}_{4}$, the bin-specific $\mathrm{NaCl}$ mass mixing ratios are summed prior to the start of each simulation.

The SCM also incorporates vertically resolved advective tendencies of total water mixing ratio and temperature from MERRA2. These tendencies from dynamics are read as 3-hourly averages and are provided on 42 atmospheric layers. Because the SCM contains its own calculations of vertical advection, tendencies of liquid/ice water potential temperature $\left(\theta_{\mathrm{li}}\right)$ and total water mixing ratio $\left(q_{t}\right)$ in the vertical direction need to be removed from the MERRA2 3D tendencies to avoid double counting. This is accomplished prior to beginning each simulation according to Eq. (1):

$$
\left(\frac{d \varphi}{d t}\right)_{\text {hor }}=\left(\frac{d \varphi}{d t}\right)_{3 \mathrm{D}}+\left(\frac{\omega}{g \rho}\right)\left(\frac{\Delta \varphi}{\Delta z}\right),
$$

where $\Delta z, \rho$, and $\omega$ are vertical profiles of SCM layer thickness, density, and vertical pressure velocity, respectively; $g$ is the gravitational acceleration at Earth's surface; and $\varphi$ is a vertical profile of either $\theta_{\mathrm{li}}$ or $q_{t}$. Surface fluxes of temperature and moisture in the SCM are provided by MERRA2.

To initialize each simulation, MERRA2 thermodynamic profiles of temperature, phase-specific water mixing ratios, and components are interpolated to the SCM 20-m vertical resolution from the lowest SCM layer center $(10 \mathrm{~m})$ to $20 \mathrm{~km}$ above sea level. Although the analyses presented here are focused on the lowest $4 \mathrm{~km}$, an accurate representation of upper-tropospheric cloudiness is important for accurate computation of radiative fluxes. At each 30-s time step MERRA2 wind components, surface latent and sensible heat fluxes, surface velocity scale, and surface skin temperature are linearly interpolated as a function of simulation time. MERRA2 skin temperature is used only for calculations of radiative heating from RRTMG. Similarly, advective tendencies of MERRA2 temperature and phase-specific water mixing ratios from dynamics are interpolated to the SCM vertical grid and then added to the subgrid tendencies computed internally by the JPL EDMF. At each time step, source terms for horizontal winds are computed according to Eq. (2):

$$
\frac{d u}{d t}=f \cdot\left(v-v_{g}\right) \quad \frac{d v}{d t}=-f \cdot\left(u-u_{g}\right),
$$

where $f$ is the Coriolis parameter; $u$ and $v$ are the prognostic eastward and northward winds from the $\mathrm{SCM}$, respectively; and $u_{g}$ and $v_{g}$ are the geostrophic winds. The geostrophic winds are approximated above the boundary layer by the time-interpolated MERRA2 horizontal winds and are held constant below the boundary layer with the value of $u_{g}$ and $v_{g}$ from the layer just above the boundary layer.

Because the calculation of radiative heating rates is one of the most computationally expensive elements of the SCM, temperature tendencies from radiation are computed every $20 \mathrm{~min}$ and assumed to be constant between computations. The exception is during the first simulation hour, when temperature tendencies from radiation are computed more often to allow clouds in the EDMF model to adjust from the MERRA2 initial conditions to its own internally consistent state.

Time-varying diurnal and synoptic conditions necessitate time-dependent updates to the forcing of the Eulerian single-column model. The simulations are therefore initialized three hours prior to the observation time and the horizontal MERRA2 advective tendencies, surface fluxes, and vertical motion are updated at each simulation time step via linear interpolation of the MERRA2 values. Our evaluation and comparison of simulated fields is performed at the end of the simulation, which occurs during the same hour that the observations are made. This procedure allows for a model spinup period, which generally requires about $10 \mathrm{~min}$. Sensitivity experiments (not shown) demonstrate little 
(a)

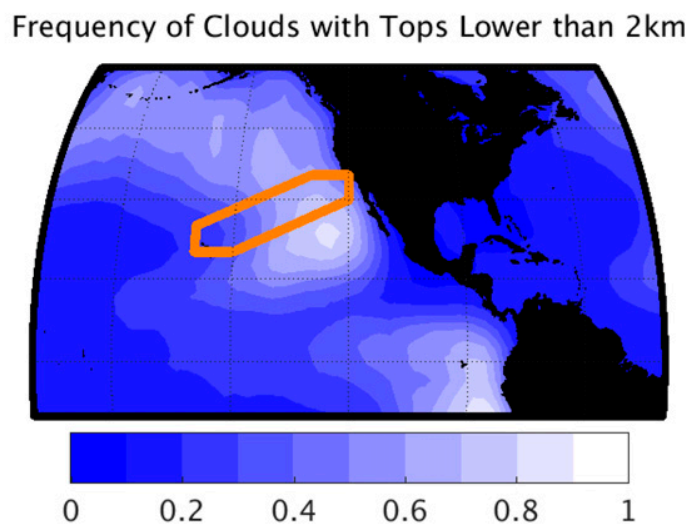

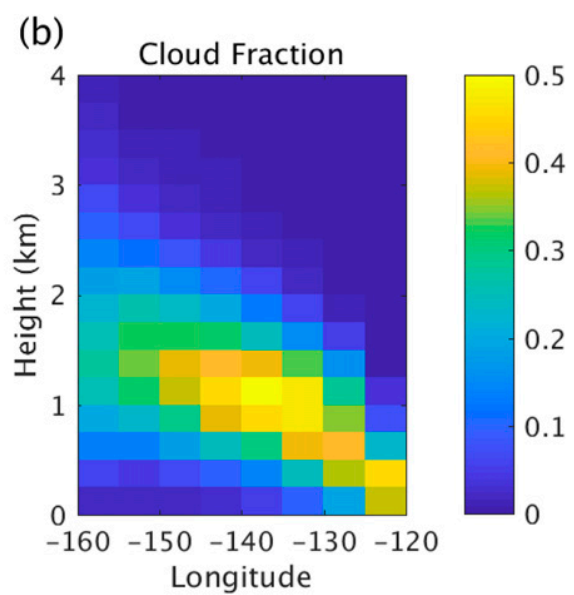

FIG. 1. (a) The MAGIC polygon study region (orange bounds) and the frequency of all scenes that a given area has its highest cloud top below $2 \mathrm{~km}$, as reported by the CloudSat 2B-GEOPROF-lidar Layer_Top, for June-JulyAugust 2007. (b) Average vertically resolved cloud fraction across the MAGIC polygon outlined in (a) derived from the merged CloudSat and CALIPSO observations described in section 3c.

sensitivity of the results to integration times of between 3 and $9 \mathrm{~h}$.

\section{b. Study domain}

The JPL EDMF was originally developed to unify the parameterization of turbulence, shallow convection, and stratiform cloudiness with a focus on the stable subtropical marine atmosphere. Specifically, in this study we focus on the transition from subtropical stratocumulus to shallow cumulus cloud regimes in the northeastern Pacific limited to a polygon bounded by Hawaii and Los Angeles, formally investigated by the shipborne Marine Atmospheric Radiation Measurement Program (ARM) GPCI Investigation of Clouds (MAGIC; Kalmus et al. 2014) observational campaign. Within the MAGIC Polygon (roughly bounding the MAGIC transect and illustrated in Fig. 1a), geographic and temporal differences in meteorology and sea surface temperature combine to produce varying frequency, coverage, and height of stratocumulus and cumulus clouds (Kalmus et al. 2014). For this initial study, we limit the simulations to the quiescent months of June, July, and August (JJA) in the year 2007. Figure 1a also shows the 2007 JJA fraction of scenes that have cloud tops below $2 \mathrm{~km}$ as reported by the CloudSat and CALIPSO observations detailed in section $3 \mathrm{c}$. Low clouds are common off the western coast of North America, but their frequency generally decreases toward the southwest corner of the MAGIC Polygon. Figure $1 \mathrm{~b}$ shows that the reduction in low cloud frequency in Fig. 1a coincides with a deepening boundary layer as cloud types transition from stratocumulus to cumulus along the trajectory of the trade winds. In this study, profiles of atmospheric state from MERRA2 contained within the MAGIC polygon during the months of JJA 2007 are used to initialize the simulations. To avoid any possible deep convection or frontal activity, we further limit the simulations to where the MERRA2 subsidence at $500 \mathrm{hPa}$ is stronger than $1 \mathrm{hPah}^{-1}$.

\section{c. Observations for assessment}

Cloud observations are taken from co-orbiting Earthobserving satellites in the A-Train satellite constellation. In a sun-synchronous orbit, the instruments aboard satellites within the A-train make their observations at about 0130 and 1330 local time. Therefore, all simulations will end during those hours. For assessment, we mainly focus on two metrics: 1) low cloud cover (LCC) defined as the maximum cloud fraction in the lowest $4 \mathrm{~km}$, and 2) cloud fraction defined as the vertical profile of the mean horizontal extent of cloud occurrence. In additional analyses we utilize observations of rain rate, top-of-atmosphere (TOA) shortwave (SW) albedo, and liquid water path (LWP) that are spatially and temporally collocated with the CloudSat observations.

To assess the performance of the JPL EDMF in producing LCC, we utilize a combination of vertically resolved cloud fraction retrievals from the CloudSat radar (2B-GEOPROF R04; Marchand et al. 2008) and from the CALIPSO lidar at the CloudSat spatial resolution (2B-GEOPROF-lidar R04; Mace and Zhang 2014). The vertical resolution of these retrievals is the $240-\mathrm{m}$ radar sampling volume and the horizontal resolution is $1.4 \mathrm{~km}$ across track and $1.7 \mathrm{~km}$ along the CloudSat orbital track with 1.1-km spacing between vertical profiles. The lidar Cloud_Fraction variable is reported as a percentage of 


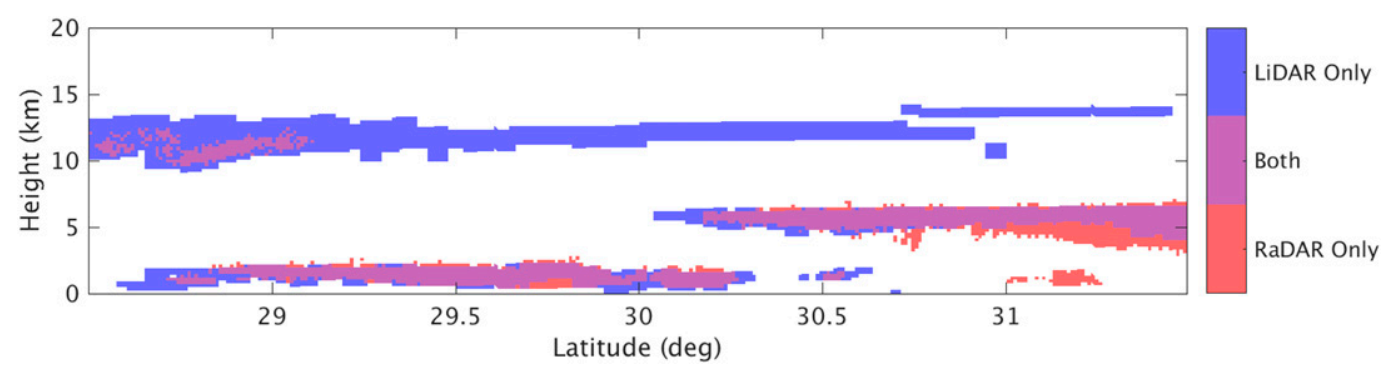

FIG. 2. Complementary cloud masks from the CloudSat radar and CALIPSO lidar during granule 05826 on 2 Jun 2007. Although any lidar cloud fraction greater than zero is displayed here, the merged CALIPSO/CloudSat observations employed in the remainder of the paper retains the lidar cloud fractions as percentages when CloudSat does not identify a layer as cloudy.

cloud-containing CALIPSO lidar volumes within a given radar volume. Radar volumes with a CPR_Cloud_mask confidence value equal-to or greater than 30 are considered fully cloudy. Figure 2 illustrates how the two sensors combine to provide a complete picture of shallow clouds over ocean. The CALIPSO/CloudSat observations used in this paper are generated for each layer and pixel as the maximum of the lidar and radar retrievals.

These combined radar/lidar observations provide a comprehensive detection of cloud top boundaries but suffer two known biases of opposite sign in the detection of cloud base. First, the radar is unable to determine cloud base in precipitating columns, which causes an overestimation of the cloud-fraction below cloud base. Second, cloud base can be undetected when the lidar is fully attenuated (at optical depth $\sim 3$ ) and where the radar reflectivity is below the radar detection sensitivity. We note that a new version of the 2B-GEOPROF-lidar product that is currently in development but not yet released suggests that the R04 data product used here does indeed overestimate the low cloud fraction, resulting from changes in the lidar-detected clouds.

Surface rain rate retrievals are drawn from the CloudSat 2C-RAIN-PROFILE release R04 "rain_rate" (L'Ecuyer and Stephens 2002; Lebsock and L'Ecuyer 2011). TOA SW albedo is determined from upwelling divided by downwelling SW radiative fluxes at the TOA by the CERESAqua instrument (Wielicki et al. 1996). For simplicity, we specifically use the "CERES SW TOA flux - upwards" and "CERES SW TOA flux - downwards" variables within the CERES-CALIPSO-CloudSat-MODIS (CCCM; RelB1 905906; Kato et al. 2010, 2011) collocation files, which are CERES observations subset along the CloudSat track. The LWP observations originate from two A-Train sensors that have been subset along the CloudSat track: the version 7 Advanced Microwave Scanning Radiometer for EOS (AMSR-E; Wentz et al. 2014) and the MODIS collection 6 (Platnick et al. 2017). The AMSR-E data are provided on a $0.25^{\circ}$ grid whereas the MODIS collection 6 has footprint of $\sim 1 \mathrm{~km}$. The microwave retrieval is based on atmospheric emission by condensed liquid water and is insensitive to the presence of overlying ice clouds. The product provides the mean LWP within in each $0.25^{\circ}$ box including clear and cloudy sky and can be interpreted as the "grid mean". More care is necessary with the MODIS LWP to derive the grid mean LWP, as the MODIS view of low liquid clouds can be obscured by overlying ice clouds in which case no estimate of the LWP can be made. To calculate the average LWP from MODIS, we assume random overlap of cirrus and boundary layers clouds by excluding any pixels identified as ice by MODIS from the calculation of the mean LWP. The grid mean MODIS LWP is then simply calculated as the fraction weighted sum of the conditional "in cloud" LWP and the clear sky pixels that have $\mathrm{LWP}=0 \mathrm{~g} \mathrm{~m}^{-2}$.

The CloudSat/CALIPSO cloud observations consist of vertical slices through the atmosphere below the satellite instead of the three-dimensional space represented by the MERRA2 initial conditions ingested by the SCM. Here, we confront the problem of determining a representative averaging length of the CloudSat/CALIPSO observational curtain of data to best represent the cloud cover over a two-dimensional area by comparing total cloud cover against coincident $1^{\circ}$ boxes of daily MODIS cloud fraction (Platnick et al. 2017). The standard deviation of differences between the two observations is shown in Fig. 3 as a function of the averaging length applied to the CALIPSO/CloudSat observations. The variability in along-track averages decreases as averaging lengths increase but reaches a minimum at about $166 \mathrm{~km}$ (151 CloudSat profiles). This averaging scale is longer than the $1^{\circ}$ MODIS grid but far less than an equivalent-area sample would be. The analogous version of Fig. 3 for the mean difference in full-column cloud cover between MODIS and CloudSat/CALIPSO is comparatively insensitive to averaging scale (not shown). Henceforth, all satellite 


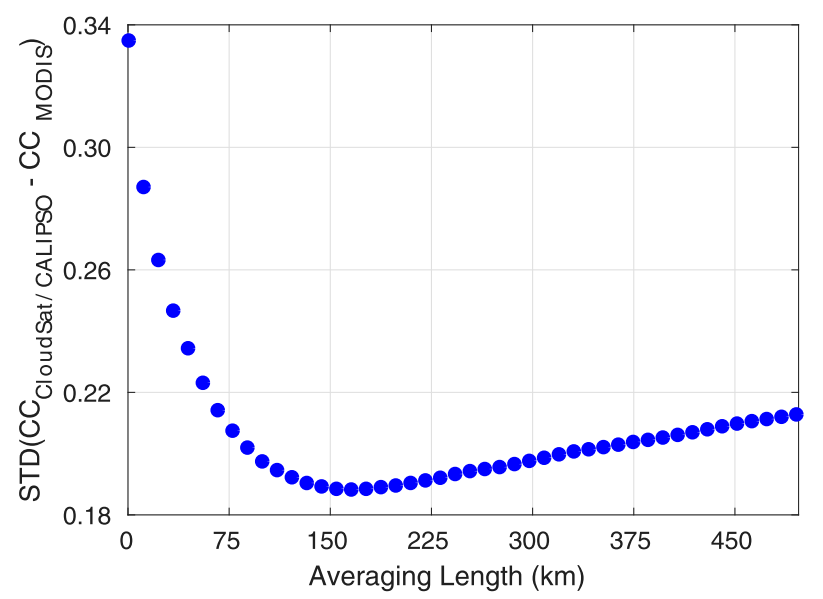

FIG. 3. Standard deviation of differences in full-column cloud cover (CC) between two-dimensional $1^{\circ}$ MODIS and CloudSat/CALIPSO as a function of averaging length. Matched MODIS and CloudSat/CALIPSO observations are included for the months of June-July-August 2007 when observations are made between the latitudes of $18^{\circ}, 36^{\circ}$ and longitudes of $-157^{\circ},-119^{\circ}$. The averaging length for which the standard deviation is minimized $(166 \mathrm{~km})$ is chosen to the observational averaging length for the remainder of this study.

observations used in this study are averaged from $83 \mathrm{~km}$ preceding to $83 \mathrm{~km}$ following the CloudSat profile that is nearest to each MERRA2 grid box center. To reduce the effects of geographical distance between the MERRA2 simulation and the observations, we require that the MERRA2 grid center be no more than $0.25^{\circ}$ from the nearest CloudSat footprint.

In total, the analysis presented here includes a total of 2044 distinct MERRA2 profiles within the MAGIC Polygon during the 2007 JJA time period with downward motion stronger than $1 \mathrm{hPa} \mathrm{h}^{-1}$ at $500 \mathrm{hPa}$ and with CloudSat footprints within $0.25^{\circ}$ from the MERRA2 grid center.

\section{d. Uncertainty analyses}

Uncertainty ranges shown in this paper consist of 5\% and $95 \%$ confidence intervals computed with bootstrap resampling (Efron 1979) of each individual mean value marked by symbols. The procedure for computing an individual bootstrap confidence interval is as follows. Figures showing uncertainty analyses are a given quantity against MERRA2 LTS. For a given MERRA2 LTS range for which there are $n$ simulations, the sample values contributing to that range are resampled $n$ times with replacement and their average value constitutes a single resample mean. Resampling is performed $10^{4}$ times, producing a distribution of $10^{4}$ resample means. The bootstrap confidence intervals are then defined as the 5 and 95 percentiles from that distribution of resample means. The process is repeated for each reported mean in each MERRA2 LTS range for the observations, JPL EDMF, and MERRA2, separately. The advantage of the bootstrap resampling method in this case is that no knowledge or assumption of the true underlying distribution is necessary. The reported confidence intervals should be used for comparison between observations, JPL EDMF, and MERRA2 and are do not necessarily bound the true environmental mean value for a given range of LTS.

\section{Performance of the JPL EDMF across LTS regimes}

Figure 4 shows an example of the evolution of the vertical profile of cloud fraction (CF) in the lowest $4 \mathrm{~km}$ over an individual 3-h simulation. Figure $4 \mathrm{a}$ shows that the JPL EDMF produces and maintains a persistent stratocumulus cloud. The thick stratus cloud is centered at about 1-km altitude and has a cloud top height just below the sharp MBL inversions of $\theta_{\mathrm{li}}$ and $q_{t}$, evident in Figs. $4 \mathrm{~b}$ and $4 \mathrm{c}$. In this particular case, the cloud is maintained throughout the 3 -h simulation. This is not necessarily the case, in general, as these clouds are free to grow or decay and raise or lower according to the advective, microphysical, and radiative tendencies acting during the simulation. In some cases, the simulations undergo a visible adjustment from the MERRA2 internally consistent state to the JPL EDMF internally consistent state. The visible adjustment occurs within the first $15 \mathrm{~min}$ of the simulations and is likely caused by a combination of differences in parameterized physics between MERRA2 and the JPL EDMF.

In this study we evaluate the JPL EDMF across all marine conditions under large-scale subsidence. Instead of defining regimes by geographical location along the MAGIC transect, we seek to categorize the simulations by defining a rough metric of the meteorological regime. The strength of the MBL-capping temperature inversion has been shown to be of great importance to low-level cloudiness in the subtropics and several metrics have been developed in order to estimate the strength of the inversion in observations and simulations. Klein and Hartmann (1993) introduce the lower-tropospheric stability (LTS) as the difference in potential temperature at the surface and at $700 \mathrm{hPa}$ and find that regions with a seasonally averaged LTS of $1 \mathrm{~K}$ greater than other regions have on average a $6 \%$ increase in stratus cloudiness. Here, LTS diagnosed from MERRA2 at the observation times (i.e., end of the simulations) as a rough measure of the weather regime against which the results will be categorized. The results are insensitive to the choice of either LTS 


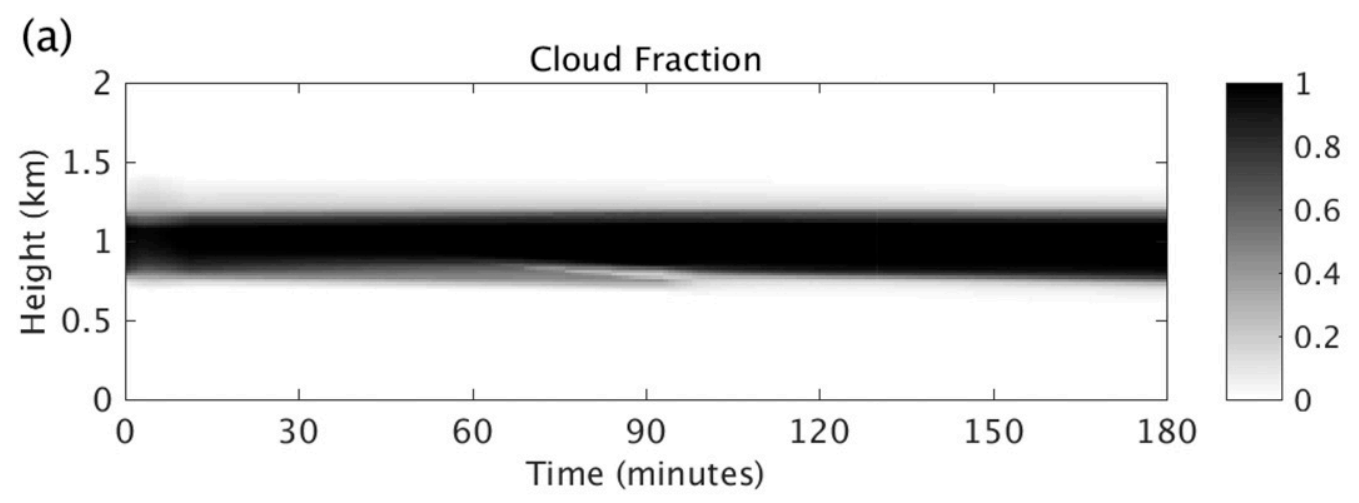

(b)

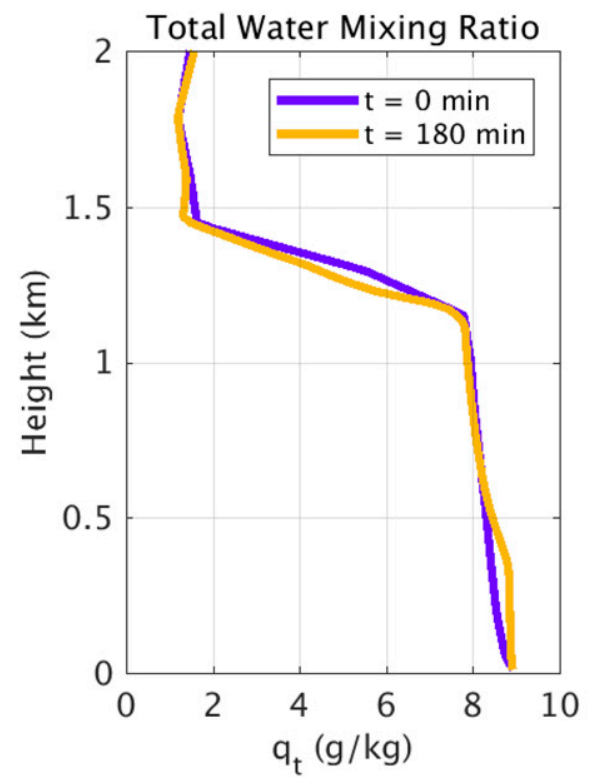

(c)

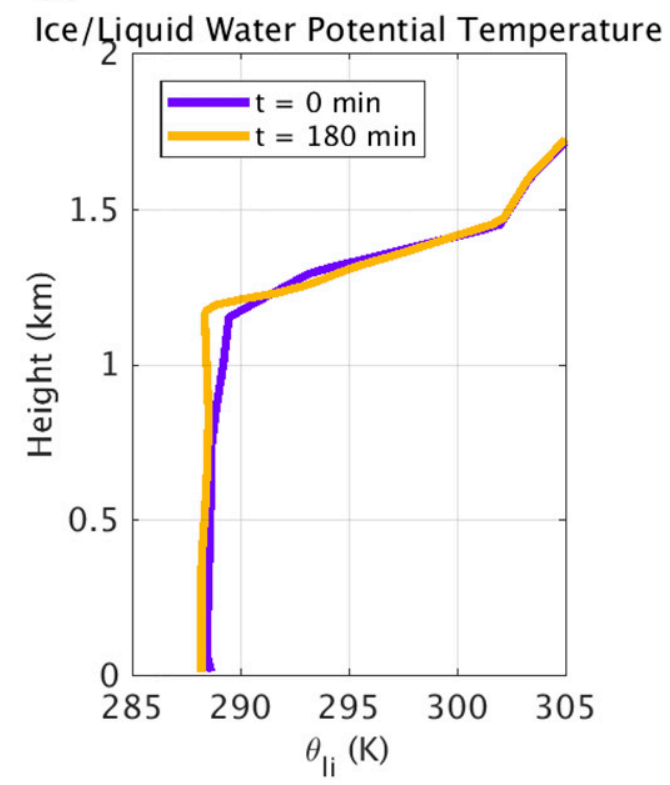

FIG. 4. Example evolution of (a) cloud fraction over a three-hour simulation located at $29.5^{\circ} \mathrm{N},-126.875^{\circ} \mathrm{E}$ and ending at 0900 UTC 3 Jul 2007. Profiles of (b) $q_{t}$ and (c) $\theta_{\text {li }}$ at the start and end of the simulation, exhibiting a steady boundary layer that evolves from the initial state supplied by MERRA2.

or the estimated inversion strength (Wood and Bretherton 2006) (not shown).

We first investigate the ability of the JPL EDMF to accurately simulate low cloud cover (LCC), defined as the maximum cloud fraction in the lowest $4 \mathrm{~km}$ assuming maximum overlap. Figure 5a shows the performance of the JPL EDMF LCC against MERRA2 LTS. A total of 2044 unique simulations contribute to Fig. 5a, with corresponding MERRA2 LTS distributed according to Fig. 5c. Mean values of LCC are shown for simulations belonging to $2.5 \mathrm{~K}$ bins of MERRA2 LTS from 10 to $30 \mathrm{~K}$ and are displayed with a small LTS offset within each bin for visual comparison. As LTS increases in Fig. 5a, the observed LCC increases until LTS increases beyond $25 \mathrm{~K}$, after which LCC decreases. The JPL EDMF is able to reproduce the general relationship of
LCC as a function of LTS, but is significantly lower in many of the LTS bins. While also reproducing the general shape of the LCC/LTS relationship as observations, MERRA2 LCC is biased low across all LTS and begins decreasing at a lower range of LTS than both the observations and the JPL EDMF.

The JPL EDMF makes clear improvements over the MERRA2 cloud cover. However, the low bias in many LTS bins suggests that in some cases the MERRA2 thermodynamic state is likely insufficiently saturated to support clouds. To demonstrate, Fig. 5b shows the results of the 1440 simulations for which the observed LCC is not more than 0.5 greater than the MERRA2 LCC. This criterion is a simple metric for eliminating simulations for which we expect that the MERRA initial conditions and forcing are inconsistent with 
(a)

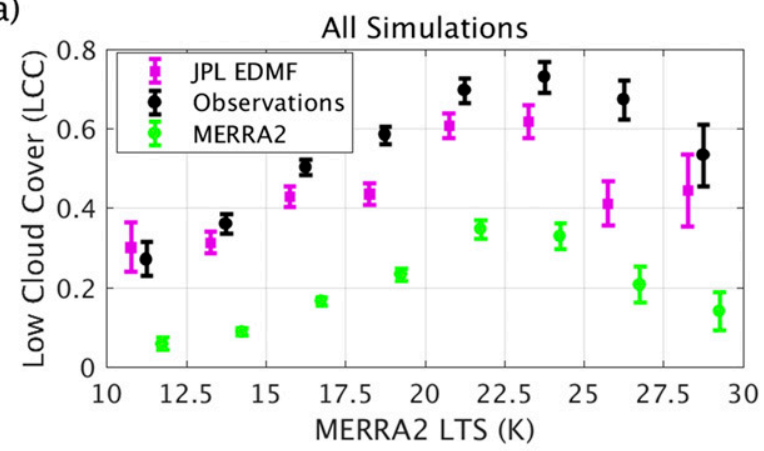

(b)

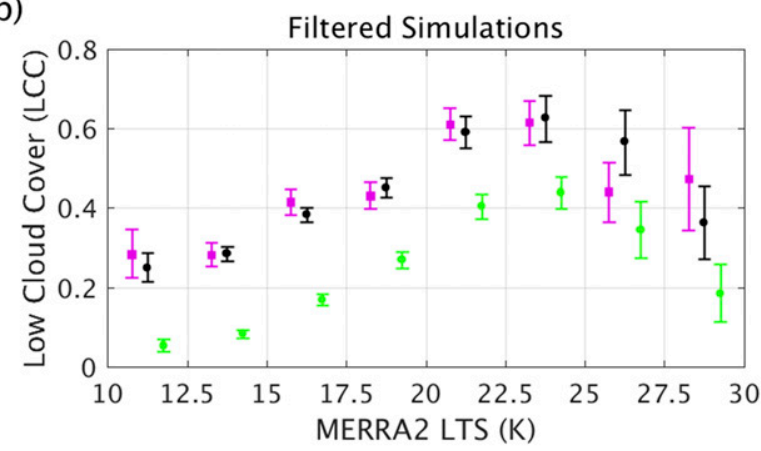

(c)

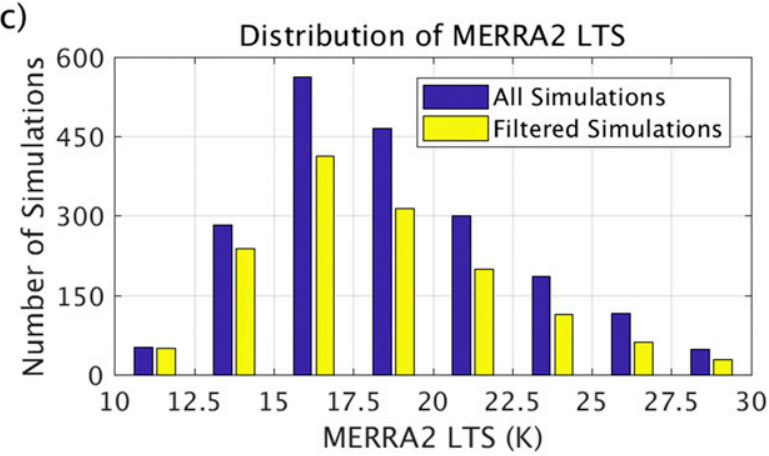

FIG. 5. (a) Mean low cloud cover (LCC) defined as the greatest cloud fraction in the lowest $4 \mathrm{~km}$ from CloudSat/CALIPSO, JPL EDMF, and MERRA2 as a function of MERRA2 LTS for 2044 simulations in the MAGIC polygon. MERRA2 LCC is computed from the CLOUD variable contained within the MERRA2 inst3_3d_asm_Nv collection. Individual values within $2.5 \mathrm{~K}$ LTS bins are offset for visibility. (b) As in (a), but excluding the 604 simulations for which the CloudSat/CALIPSO LCC is more than 0.5 greater than the MERRA2 LCC for a total of 1440 simulations. (c) Histogram of MERRA2 LTS at the end of the simulations. Results are grouped in $2.5 \mathrm{~K}$ bins of MERRA2 LTS with edges from 10 to $30 \mathrm{~K}$.

observations. The agreement between the JPL EDMF and observed LCC improves to within the uncertainty ranges. The close agreement between JPL EDMF and the observations across the range of LTS indicates the proficiency of the model in producing accurate low cloud cover across a wide range of subtropical marine conditions when the provided initial state and forcings are consistent with observations. Figure $5 \mathrm{c}$ shows the distribution of MERRA2 LTS in the All-2044 simulation and Filtered-1440 simulation sets. In all, about $30 \%$ of simulations are discarded using this criterion. We note that the behavior of the model and the conclusions of analyses that follow in this paper are not significantly altered by using the Filtered 1440-simulation set. We therefore continue with all 2044 simulations, while noting that the JPL EDMF is expected to be biased low in cloud cover due to deficiencies in the model inputs from MERRA2.

In addition to the relationship between mean LCC and LTS, we also examine the full frequency distribution of LCC. Figure 6a shows the observed frequency of LCC as a function of MERRA2 LTS. In low-LTS conditions, observed LCC tends to be low and the distribution shifts toward higher LCC with increasing LTS. This shift is also realized to differing extents by the JPL EDMF (Fig. 6b) and by MERRA2 (Fig. 6c). At high LTS, the JPL EDMF agrees well with observations in producing frequent LCC of greater than 0.9, a condition almost never realized by MERRA2. However, the JPL EDMF does not produce the observed consistent and smooth increase in LCC as a function of LTS. The JPL EDMF produces high LCC more frequently than is observed when LTS is lower than about $15 \mathrm{~K}$. It also appears that the JPL EDMF produces too few instances of moderate LCC between about 0.3 and 0.8 compared to the observations. This analysis has shown that the JPL EDMF is able to fully reproduce the observed relationship between average LCC and LTS (Fig. 5) but that it lacks the observed statistically smooth transition from stratocumulus to cumulus cloud types with decreasing LTS. This conclusion is possible due to the high number of unique simulations performed in this parameterization development framework.

Figure 7 illustrates the behavior of the vertical profile of cloud fraction from observations (Fig. 7a), JPL EDMF (Fig. 7b), and MERRA2 (Fig. 7c) as a function of LTS regime. To address the differing vertical resolutions of CloudSat/CALIPSO, JPL EDMF, and MERRA2, the vertical profiles of cloud fraction have been computed as the maximum cloud fraction in each $250-\mathrm{m}$ vertical bin. While the three datasets exhibit roughly the same basic shape (clouds tend to occur lower when LTS is higher), there are important differences worth noting. First, the observations (Fig. 7a) show more cloudiness than JPL EDMF (Fig. 7b) and MERRA2 (Fig. 7c) at all LTS ranges, although the cloud fraction from the JPL EDMF is much closer to the CloudSat/CALIPSO observations than MERRA2 is. Second, the height of JPL EDMF cloudiness agrees most closely with MERRA2, while the observed cloud 
(a)

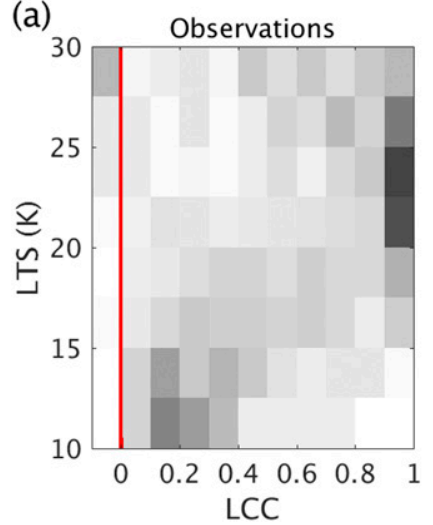

(b)

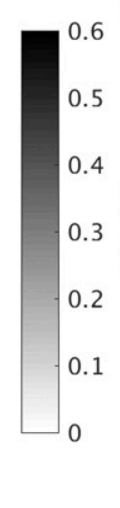

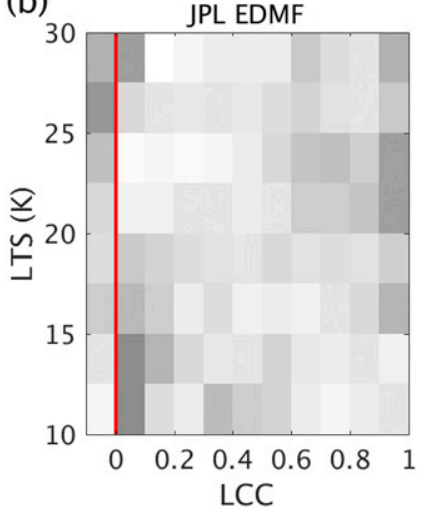

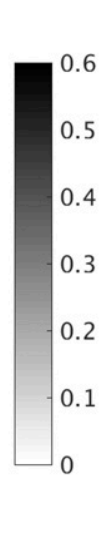

(c)

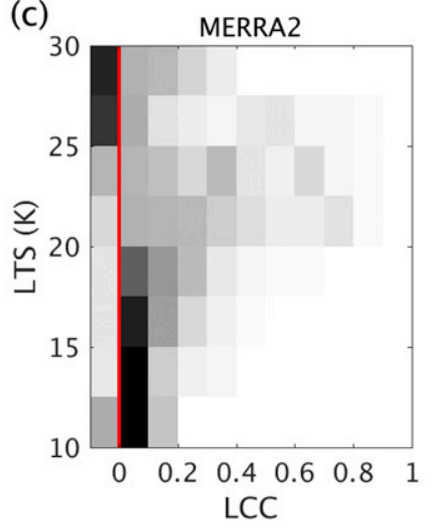

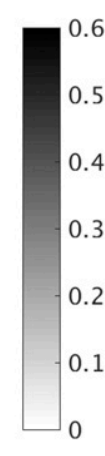

FIG. 6. Relative frequency of LCC values from (a) CloudSat/CALIPSO, (b) JPL EDMF, and (c) MERRA2 as a function of MERRA2 LTS. Instances of LCC $=0$ are shown to the left of the red LCC $=0$ line, while instances of LCC $=1$ are included in the highest LCC range.

fraction profiles are more sensitive to LTS. This shows that while the representation of LCC improves dramatically over MERRA2, the JPL EDMF is to a large extent constrained by the thermodynamic structure of the MERRA2.

The framework employed in this study permits a detailed assessment of not only the average cloud fraction, but also the frequency distribution of simulated cloud fractions. Figure 8 shows the relative frequency of cloud fraction as a function of height from observations, JPL EDMF, and MERRA2. Note that the mean cloud fractions are repeated in Figs. $8 \mathrm{a}-\mathrm{c}$, whereas the gray shaded frequencies are unique for each panel. Of particular interest here is the bimodal distribution of the observations at about $1-\mathrm{km}$ altitude with modes near $0 \%-0.2 \%$ and $100 \%$ cloudiness. The JPL EDMF successfully reproduces this behavior despite the fact that its initial conditions and advective tendencies are derived from MERRA2, which very rarely produces cloud cover near $100 \%$. Despite the improvement of the JPL EDMF over the MERRA2 cloudiness, the average cloud fraction from the JPL EDMF is still less than the observed cloud fraction throughout much of the lowest $4 \mathrm{~km}$. The JPL EDMF underestimates cloud fraction below $0.5 \mathrm{~km}$ and above $1.5 \mathrm{~km}$, where cloud fractions between 0.2 and 0.6 are often observed. As concluded from Fig. 7, this is likely due to the JPL EDMF being constrained by the thermodynamic structure of the MERRA2 initial states and forcings.

Though this study focuses on the representation of cloud cover, Fig. 9 illustrates the performance of the JPL EDMF in reproducing other cloud-related quantities, namely liquid water path (Fig. 9a), top-of-theatmosphere (TOA) shortwave (SW) albedo (Fig. 9b), and rain rate (Fig. 9c). In simulations with the highest MERRA2 LTS, the JPL EDMF simulates similar (a)

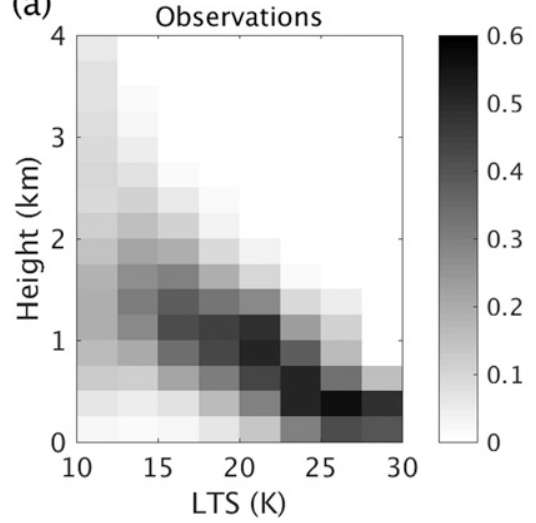

(b)

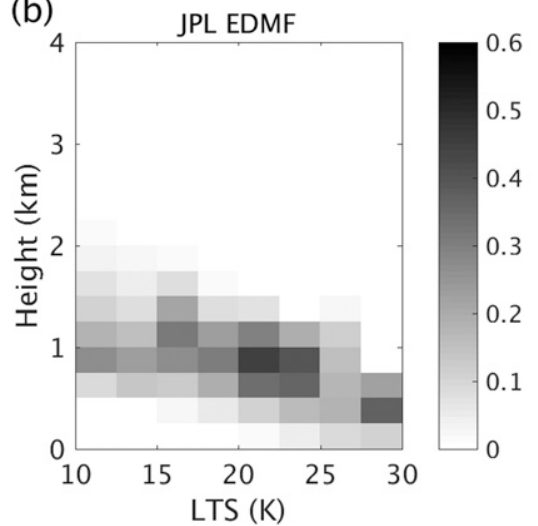

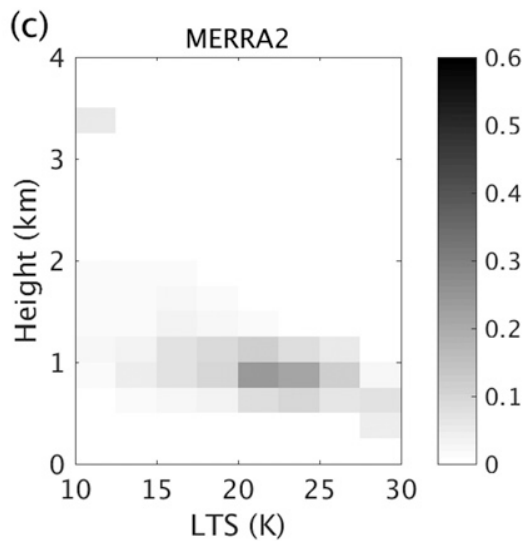

FIG. 7. Mean vertical profiles of cloud fraction from (a) CloudSat/CALIPSO, (b) JPL EDMF, and (c) MERRA2 as a function of MERRA2 LTS at the end of each simulation. 
(a)

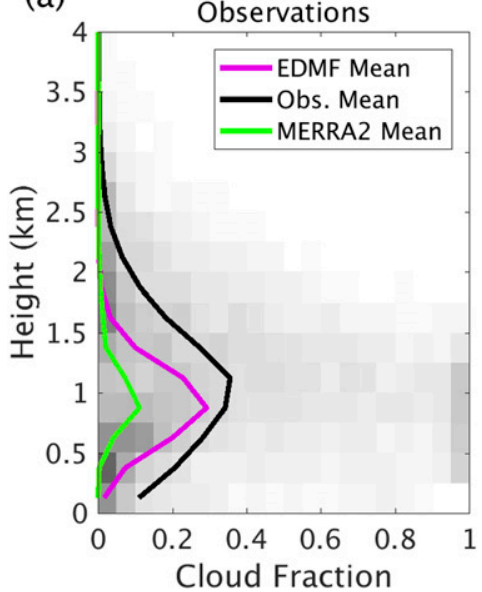

(b)

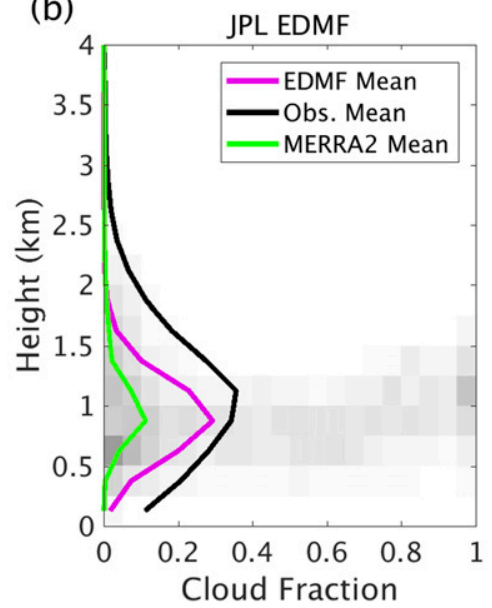

(c)

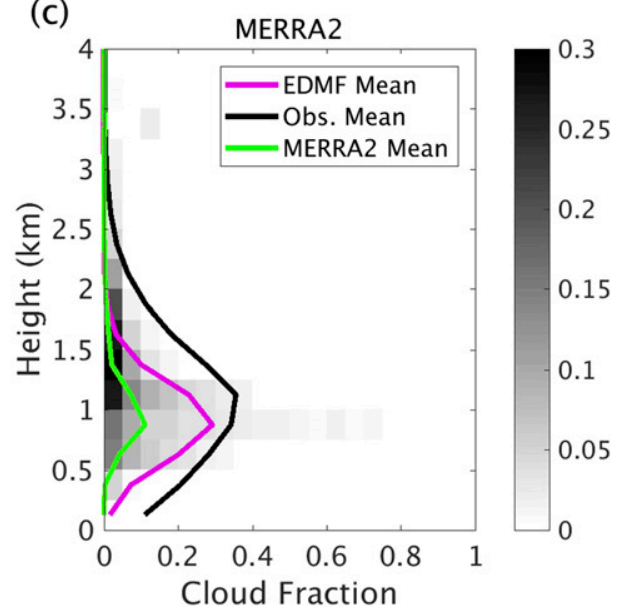

FIG. 8. Grayscale relative frequencies of cloud fraction values as a function of height for all simulations at 0.05 resolution in cloud fraction and 250-m resolution in height for (a) CloudSat/CALIPSO, (b) JPL EDMF, and (c) MERRA2. Instances of cloud fraction $=0$ are not shown. Mean cloud fraction profiles are shown as lines in each box for direct comparison.

grid-mean LWP as observed by independent but collocated AMSR-E and MODIS observations but is biased slightly below observations in most other LTS ranges (Fig. 9a). Note that in the low-LTS conditions suitable for shallow convection, AMSR-E retrievals can be interpreted as an upper bound on LWP because its estimates can be biased high due to the effects of precipitation (Greenwald et al. 2018) and MODIS retrievals of liquid water path can be biased low to its inability to retrieve thin clouds near cloud edges (Lebsock and Su 2014). In this low-LTS regime, the JPL EDMF modeled LWP falls slightly below what is retrieved by MODIS, while MERRA is significantly higher than either observation.

In Fig. 9b, the JPL EDMF is shown to accurately depict the mean behavior of observed TOA SW albedo at low LTS, which is intuitive due to the close agreement in LCC (Fig. 5a). At high LTS, the low bias in LCC from JPL EDMF results in a low bias in albedo. We note that if the Filtered 1440-simulation set is used, the JPL EDMF agrees with observed albedo to within the uncertainty bounds (not shown). Perhaps most interesting is the exemplary performance of the MERRA2 albedo at low LTS, as the MERRA2 cloud fraction is biased low compared to observations even in this range. The answer may lie with the excessively large MERRA2 LWP, demonstrating the common 'too bright too few' cloud phenomena in global models.

Precipitation acts as sink of $q_{t}$ from the cloud layer and has been shown in LES simulations to cool the subcloud layer through evaporation of rain drops, thereby stratifying the subcloud layers and altering the environment convection encounters as it rises (Sandu and Stevens 2011).
In terms of surface rain rate, the JPL EDMF agrees well with the observations (Fig. 9c), while the MERRA2 rain rates are relatively insensitive to MERRA2 LTS and too low in the low LTS regimes. It is encouraging to see such close agreement between simulated and observed rain rates without using the rain rate as an evaluation metric in the tuning process for cloudiness. This success may be the result of a consistent coupling of the nonlinear microphysical process to the subgrid-scale assumptions of the EDMF. Over stratocumulus regions roughly $50 \%$ of precipitation evaporates before reaching the surface (Rapp et al. 2013), which results also in a moistening and cooling of the subcloud layer. There is some reason to believe that microphysics plays a role in the stratocumulus to cumulus transition (Yamaguchi et al. 2017) and accurate representation of these rather small rain rates may be important for climate simulations of cloud feedbacks.

\section{Sensitivity to choices of lateral entrainment and vertical turbulent mixing parameters}

Results from the previous section show that with an optimal parameter set the JPL EDMF is able to reproduce key features of the transition in cloudiness across a range of environmental conditions. Here we show the sensitivity of simulated cloud properties to two important parameters controlling the lateral entrainment into convective plumes and turbulent mixing. In so doing we also investigate the physical mechanisms through which the plume lateral entrainment and turbulent mixing influence the simulated cloudiness. 
(a)

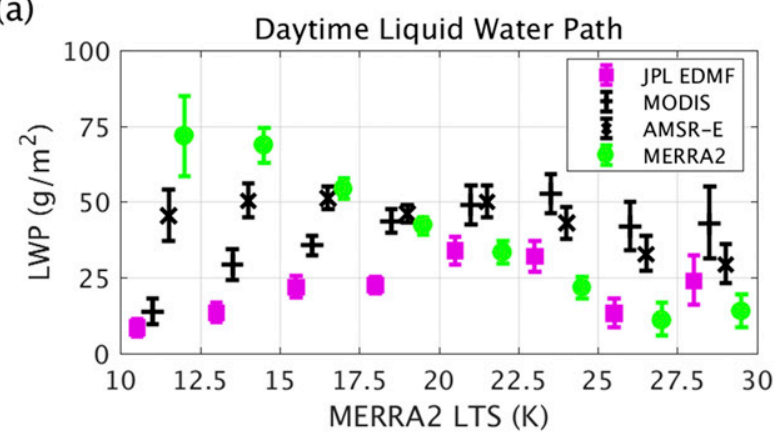

(b)

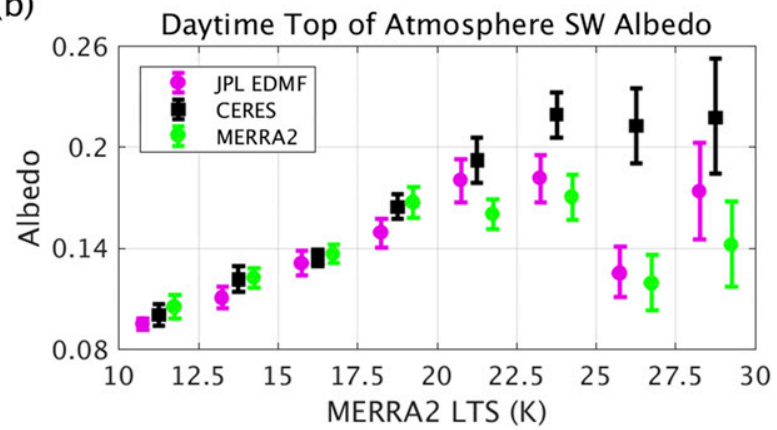

(c)

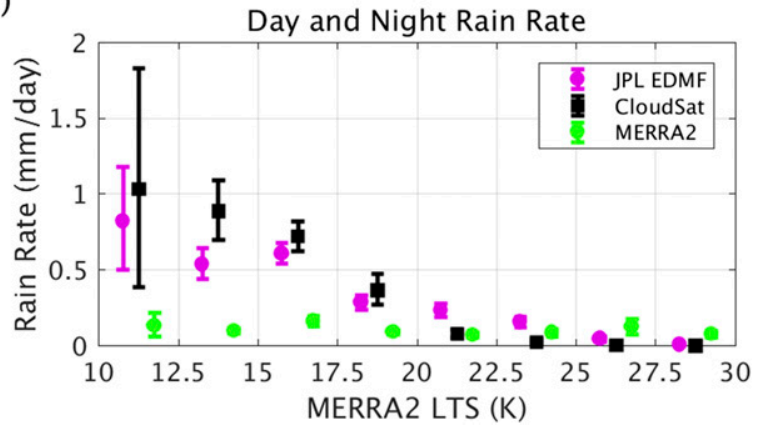

FIG. 9. End-of simulation mean (a) daytime liquid water path, (b) daytime TOA SW albedo, and (c) day and night rain rate as a function of MERRA2 LTS. Individual values within LTS bins are offset for visibility.

The first parameter $w_{0}$ [Eq. (A4)], influences the expected frequency of stochastic lateral entrainment events in the updraft plumes. Increasing $w_{0}$ will, on average, result in more frequent lateral entrainment events, while the amount of the entrained air per lateral entrainment event is kept constant. Therefore, increasing parameter $w_{0}$ increases the mean lateral entrainment rate for convective plumes. The second parameter is $A_{s}$, a multiplier applied to the parameterized mixing length in the eddy-diffusivity portion of the parameterization in layers where the Richardson number is greater than 0.01 [Eq. (A9)]. The formulation is intended to decrease the mixing of warm dry air across the MBL inversion layer in high-LTS conditions when the $A_{s}$ is decreased, effectively decreasing the mixing across the stratocumulus cloud top. Together, $A_{s}$ and $w_{0}$ exert strong influences on the vertical fluxes of $\theta_{\mathrm{li}}$ and $q_{t}$ and therefore the simulated cloudiness.

Because the JPL EDMF is computationally efficient when implemented within a SCM framework, we are able to directly examine the effects of many different choices of parameter value combinations on average simulated LCC. Figure 10 shows the average LCC of simulations performed on all 2044 distinct MERRA2 initial conditions at each of the displayed lateral entrainment and turbulent mixing parameter combinations. The inset box marks the default JPL EDMF parameter combination used throughout section 4 $\left(w_{0}=126 \mathrm{~m} \mathrm{~s}^{-1 / 2}, A_{s}=10^{-6} \mathrm{~s}^{-2}\right)$.

When averaged over all simulations, LCC increases with increasing plume lateral entrainment and decreasing turbulent mixing in stable layers (Fig. 10a). Increasing plume lateral entrainment ( $w_{0}$ in Fig. 10a) increases the chances that plumes will become diluted and reach neutral buoyancy before passing through the boundary layer inversion, which would have transported moist air out of the MBL and decreased MBL cloudiness. High plume lateral entrainment tends to prevent this drying mechanism from initiating the transition from stratocumulus into cumulus boundary layers. Decreasing turbulent mixing ( $A_{s}$ in Fig. 10a) across the inversion layer decreases the mixing of warm, dry air from above the cloud deck into the cool moist cloud layer, which also favors high values of LCC.

Using the default parameter combination results in an average LCC that closely agrees with observations (Fig. 5a). However, Fig. 10b shows that there is a range of good agreement in average LCC across tested parameter combinations, especially at lower values of $A_{s}$ when $w_{0}$ is about $126 \mathrm{~m} \mathrm{~s}^{-1 / 2}$ and at higher values of $w_{0}$ when $A_{s}$ is about $10^{-5}$. To identify the optimal values, it is necessary to examine LCC conditioned by weather regime, as the $w_{0}$ and $A_{s}$ parameters are not expected to equally affect the simulations in all environmental conditions.

Figure 11a shows the sensitivity of the simulated LCC from the JPL EDMF to various combinations of $w_{0}$ and $A_{s}$ as a function of LTS. The relationship between simulated LCC and LTS depends strongly on the choice of lateral entrainment and turbulent mixing parameters. Interpreted another way, the sensitivity of LCC to $w_{0}$ and $A_{s}$ depends strongly on LTS. When LTS is low, the LCC is highly sensitive to the JPL EDMF plume lateral entrainment parameter $w_{0}$. In this regime the LCC is largely controlled by the efficiency with which convection dries the near-surface layer and moistens the layers above the cloud layer. When LTS is high the LCC is 
(a)

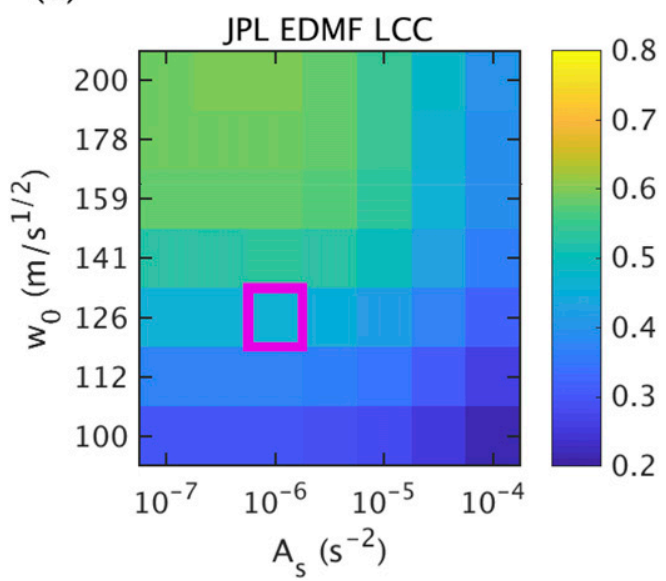

(b)

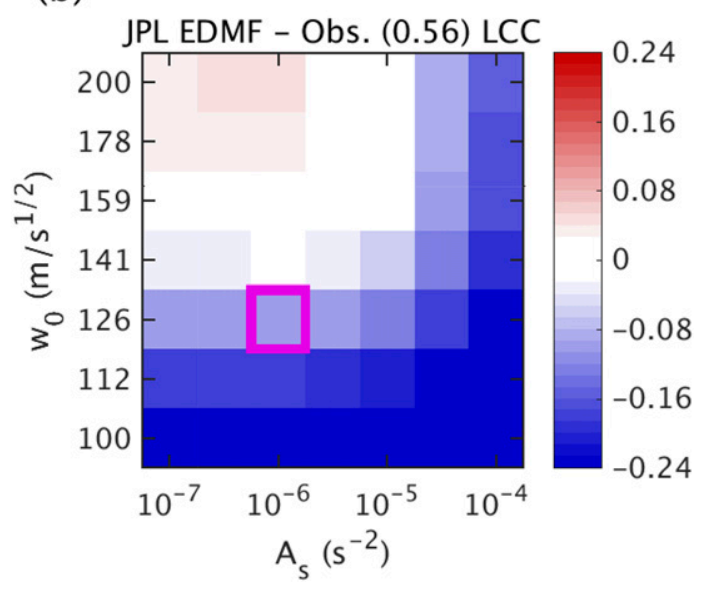

FIG. 10. (a) Average JPL EDMF LCC as a function of parameters related to plume lateral entrainment $\left(w_{0}\right)$ and turbulent mixing $\left(A_{s}\right)$. (b) Differences in JPL EDMF LCC shown in (a) from CloudSat/CALIPSO, which have an average LCC of 0.56 regardless of JPL EDMF parameters. The default values for $A_{s}$ and $w_{0}$ are $10^{-6} \mathrm{~s}^{-2}$ and $126 \mathrm{~m} \mathrm{~s}^{-1 / 2}$, respectively, and are labeled by a box in (a) and (b).

primarily sensitive to turbulent mixing of free tropospheric dry air into the boundary layer controlled in part by the parameter $A_{s}$. In high-LTS conditions there is little that the JPL EDMF model physics can do to increase LCC beyond the displayed values, suggesting that many of the high-LTS ancillary profiles from MERRA2 simply cannot create and maintain high values of LCC. The default parameter combination represents a balance of plume lateral entrainment and turbulent mixing, which results in the most accurate simulations of LCC across a wide range of LTS, as was illustrated in Fig. 5a.

The effects of $w_{0}$ on plume lateral entrainment can be seen directly in Fig. 11b. As shown by Eqs. (A3) and (A4), increasing $w_{0}$ increases the mean lateral entrainment rate in plumes by decreasing the expected distance a plume is raised before encountering a lateral entrainment event. Figure $11 \mathrm{~b}$ shows that high-LTS profiles are characterized by shorter plume lateral entrainment-scale lengths, which leads to higher plume lateral entrainment rates and the inability of convection to dry the boundary layer by transporting moisture out of the MBL and disrupting the strong temperature and moisture inversion.

Figures $11 \mathrm{c}$ and $11 \mathrm{~d}$ show how $A_{s}$ directly affects the turbulent mixing length for heat ( $l_{h}$; Sušelj et al. 2013). This mixing length is much shorter in areas above the boundary layers in high-LTS conditions when the $A_{s}$ is small (Fig. 11c) than when it is a factor of 100 larger (Fig. 11d). On the other hand, the mixing within the boundary layer is largely unaffected. Differences between Figs. $11 \mathrm{c}$ and $11 \mathrm{~d}$ illustrate the impact of the $A_{s}$ parameter in controlling small-scale mixing across the top of the marine boundary layer, which is labeled by black lines and is defined as the height of the lowest local minimum in upward temperature flux where the upward temperature flux is less than 0 .

Close inspection of $l_{h}$ just above and below the boundary layer top in Figs. $11 \mathrm{c}$ and $11 \mathrm{~d}$ reveals $l_{h}$ is actually longer when $A_{s}$ is smaller. This is likely due to the fact that mixing within the cloud layer is important to the maintenance of stratocumulus clouds. Indeed, the $A_{s}=$ $10^{-4} \mathrm{~s}^{-2}$ simulations produce reduced LCC at high-LTS (Fig. 11a), which lowers the average $l_{h}$ in those layers directly below the inversion. This highlights the important function of this parameter to limit mixing across the inversion without simultaneously decreasing the mixing within the boundary layer necessary to maintain the cloud layer. Because Figs. 10 and 11a show that limiting $A_{s}$ to even smaller values does not significantly change simulated LCC, the default value of $10^{-6} \mathrm{~s}^{-2}$ is selected as further reducing its value results in extremely small and nonphysical values of $l_{h}$ just above the cloud layer.

The sensitivity of the simulated thermodynamic profiles to $w_{0}$ and $A_{s}$ are illustrated in Fig. 12. Here the differences in profiles of $q_{t}$ and $\theta_{\mathrm{li}}$ are shown for several perturbed parameter combinations also investigated in Fig. 11. The data are subset into highest (top row) and lowest (bottom row) LTS quartiles of the 2044 simulated cases. The vertical profiles in Fig. 12 are presented with a normalized height scale with the halfway point set at the height of the temperature inversion, defined in the same manner as in Figs. 11c and $11 \mathrm{~d}$ as the height of the lowest local minimum in upward temperature flux where the upward temperature flux is less than 0 . After identifying the inversion level for each profile, profiles of cloud fraction, $q_{t}$, and $\theta_{\mathrm{li}}$ are 
(a)

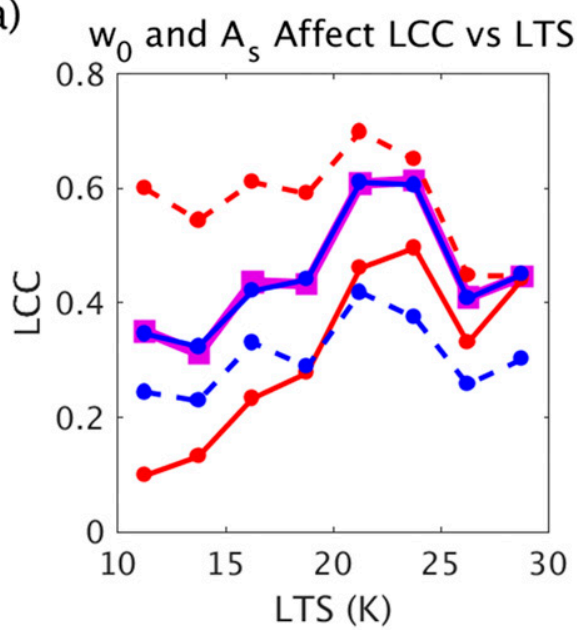

(b)

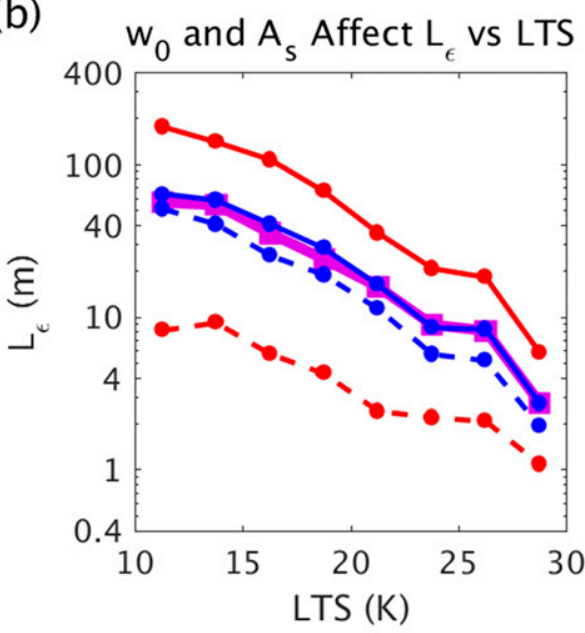

$$
\begin{array}{r}
\longrightarrow-\mathrm{w}_{0}=100 \mathrm{~A}_{\mathrm{s}}=10^{-6} \\
-\bullet-\mathrm{w}_{0}=200 \mathrm{~A}_{\mathrm{s}}=10^{-6}-\mathrm{w}_{0}=126 \mathrm{~A}_{\mathrm{s}}=10^{-6} \longrightarrow-\mathrm{w}_{0}=126 \mathrm{~A}_{\mathrm{s}}=10^{-7} \\
-\bullet-\mathrm{w}_{0}=126 \mathrm{~A}_{\mathrm{s}}=10^{-4}
\end{array}
$$

(c)

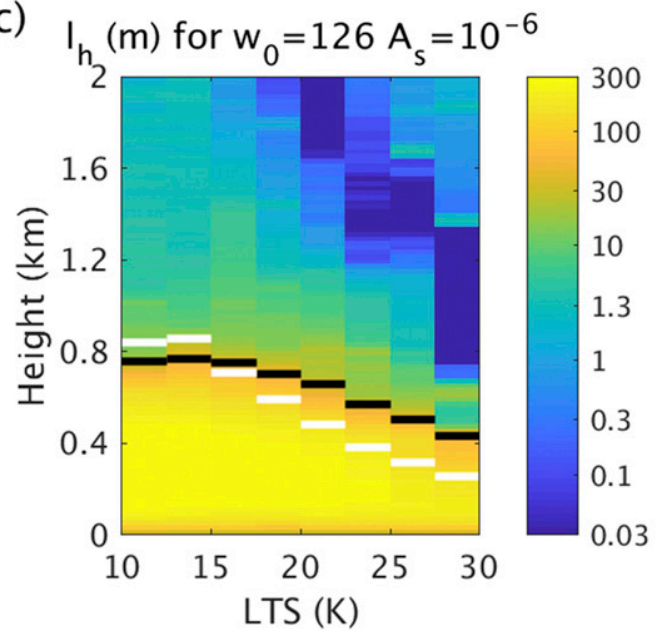

(d)

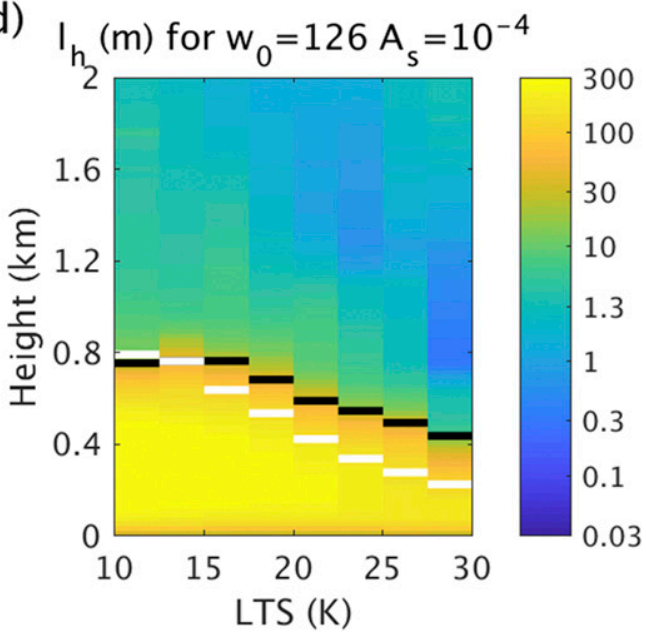

FIG. 11. JPL EDMF (a) LCC and (b) plume lateral entrainment length scale $L_{\varepsilon}$ as a function of MERRA2 LTS for various $w_{0}$ and $A_{s}$ combinations. Also shown are mean vertical profiles of JPL EDMF eddy-diffusivity mixing lengths for heat $\left(l_{h}\right)$ as a function of MERRA2 LTS when (c) the $A_{s}$ mixing parameter is set to the default value $10^{-6} \mathrm{~s}^{-2}$ and (d) when the $A_{s}$ parameter is increased by a factor of 100 . In (c) and (d), black and white lines illustrate the mean boundary layer height and the mean height of the tallest mass-flux plume at the end of each simulation, respectively.

stretched proportionally to reach the surface, "Inv," and $4-\mathrm{km}$ boundaries.

For the high LTS quartile, increased cloud-top turbulent mixing when $A_{s}$ is set too high results in slight warming from the surface to near the inversion (Fig. 12c), with considerable cooling just above the inversion level. At the same time, the air just above the inversion level tends to have more total water (Fig. 12b) due to the increased mixing of temperature and moisture from below the inversion. A similar effect occurs when $w_{0}$ is set too low, albeit with little warming of the mixed layer. In this case, it is likely that the reduced entrainment rate allows for too much convection in high-LTS cases, which destroys the strong temperature and moisture inversion that is necessary for uniform cloudy layers on the scale of the MERRA2 grid box $\left(\sim 0.5^{\circ}\right)$.

For the low LTS quartile, decreased plume lateral entrainment dries the atmosphere below the weak inversion and within the cloud layer (Fig. 12e). The associated decrease in cloudiness is shown in Fig. 12d below 
(a)

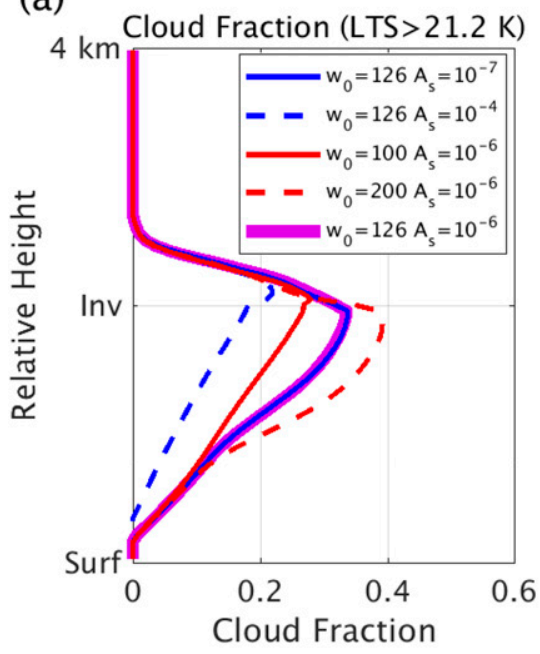

(d)

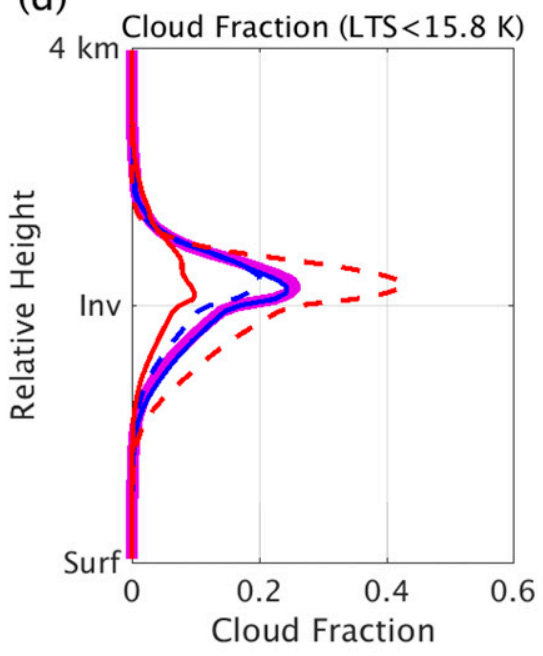

(b)

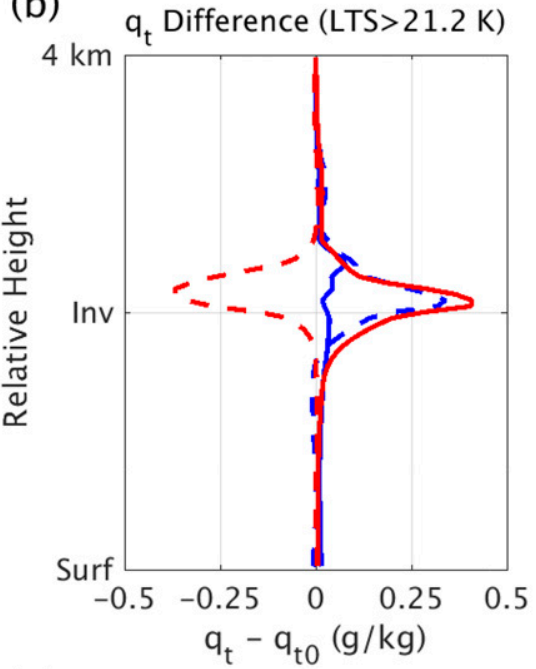

(e)

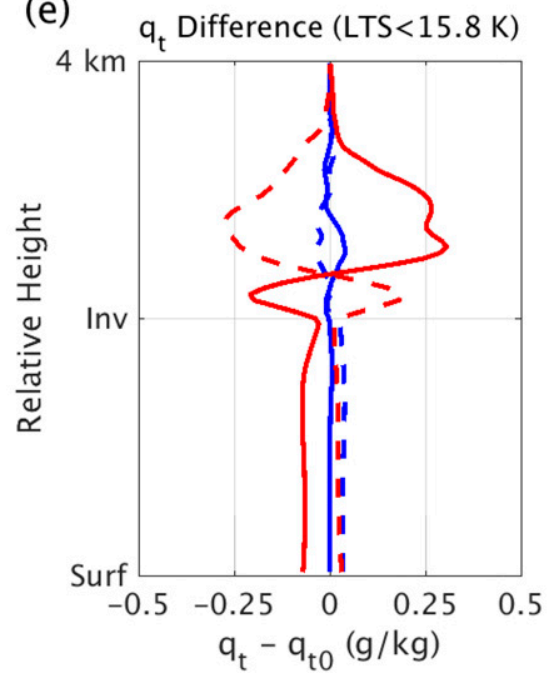

(c)

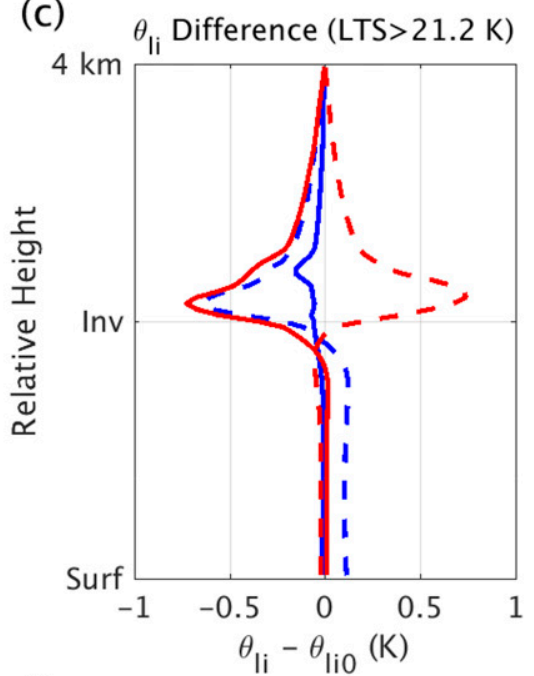

(f)

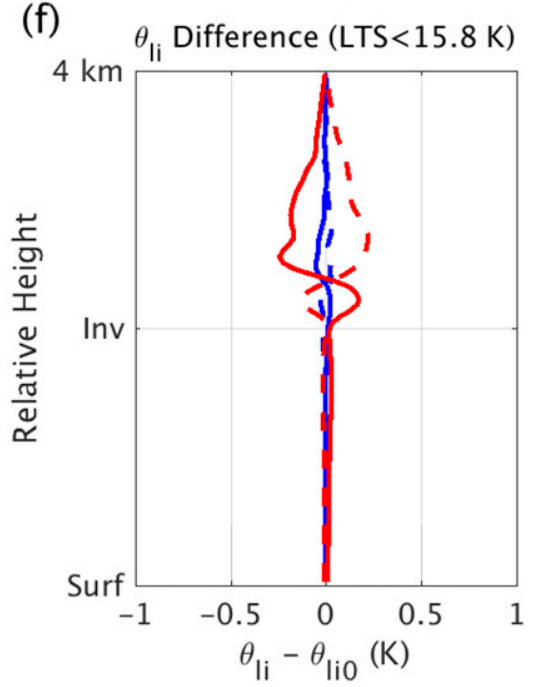

FIG. 12. (a) Mean cloud fraction for various combinations of $w_{0}$ and $A_{s}$ on a normalized height coordinate where "Inv" denotes the location of the inversion level of individual simulations for the highest quartile of MERRA2 LTS. (b), (c) Differences in simulated $q_{t}$ and $\theta_{\mathrm{li}}$ from the default JPL EDMF $\left(A_{s}=10^{-6} \mathrm{~s}^{-2}, w_{0}=126 \mathrm{~m} \mathrm{~s}^{-1 / 2}\right)$ for the same high-quartile LTS simulations. (d)-(f) As in (a)-(c), but for the simulations belonging to the lowest quartile of MERRA2 LTS.

and just above the inversion layer. The enhanced convection also slightly increases cloud fraction above the stratus cloud layer. On the other hand, too much plume lateral entrainment leads to a moistening of the stratus layer as plumes draw more water vapor upward to the inversion level but are unable to lift them into the free troposphere (Fig. 12e), causing an increase in cloudiness in the stratus layer but a decrease in relative humidity above. Turbulent mixing plays a reduced role in determining cloud fraction in these low-LTS simulations.

This analysis has shown that JPL EDMF low cloud cover is most sensitive to minimizing cloud-top turbulent mixing in high-LTS regimes and sensitive to the choice of plume lateral entrainment rate in all tested regimes. In intermediate LTS regimes, simulations of
LCC are sensitive to the balance of both physical processes. Accurate tuning of these parameters has required the analysis of a large number of cases across the climatological transition from stratocumulus to shallow cumulus marine boundary layers.

\section{Summary}

This paper demonstrates a new and promising method for developing and tuning physical parameterizations used in atmospheric models. We propose this strategy as a complementary approach for parameterization development. The essence of proposed approach is to run parameterization within a single-column model initialized and forced by weather reanalyses and validate 
against observational benchmarks from satellites. This approach has several advantages over traditional methods, namely: 1) it is computationally efficient, allowing for an exploration of parameter space and alternative descriptions of physical processes, 2) it is able to isolate differences resulting from varying model parameters or model physics from differences due to feedbacks from large-scale circulation in GCMs, 3) its results capture widely varying weather conditions that are lacking in averaged field campaign profiles frequently used in LES-based tuning, and 4) it employs vertically resolved observations that have global coverage as a check on simulations initialized by global weather reanalyses, encouraging further parameterization development in other regions and weather regimes. While this study is focused on the JPL EDMF representation of the transition of stratocumulus to cumulus cloud types over the subtropical northeast Pacific Ocean, the method described here may be employed for the development of virtually any parameterization suitable for atmospheric models within any region of interest where satellite observations are available.

The novel framework sets up a controlled experiment in which the JPL EDMF parameterization is embedded within a single-column model (SCM) and then initialized and forced with diverse thermodynamic conditions from a global weather reanalysis. After validating the JPL EDMF against near-globally available satellite observations, the sensitivity of the simulations to convective plume lateral entrainment and small-scale turbulent mixing were explored to identify optimal model physics and parameter values. Results are grouped according to the lower-tropospheric stability (LTS) as diagnosed from MERRA2 at the time of satellite overpass, which serves as a simple proxy for weather regime.

This framework is not without its challenges. Most significantly the biases in the MERRA2 reanalysis data that are used to initialize and force the SCM might reflect on the simulation results. Using a simple metric dealing with the difference in observed and MERRA2 LCC, we showed that about $30 \%$ of simulations are associated with MERRA2 initial conditions and forcings that have a large disagreement with the observed atmospheric state.

Future work will investigate the influence of the choice of weather reanalyses used to initialize and force the single-column model and further evaluate the method using observation-based forcing datasets produced for heavily instrumented surface sites such as the eastern North Atlantic site on the Azores (Wood et al. 2015). Despite the certain deficiencies in the reanalysis data, we believe that this framework is valuable and complementary to more traditional forms of parameterization development because the computational efficiency of the single-column model permits the investigation of many unique samples over a wide range of weather conditions.

Using all 2044 simulations, the JPL EDMF was shown to improve upon the MERRA2 LCC relationship to LTS. When using only simulations where there was no large discrepancy between MERRA2 and observations, the JPL EDMF was shown to reproduce observed mean low-level cloud cover as well as its relationship to LTS to within sampling uncertainty. In addition, the JPL EDMF is able to reproduce the observed bimodal distribution of cloud cover which includes frequent occurrence of $100 \%$ cloud cover at about $1-\mathrm{km}$ altitude. However, it was also shown that the JPL EDMF is reluctant to produce a smooth transition from stratocumulus to cumulus clouds, which is required for the transition from stratocumulus to cumulus cloud types. This is partially due to producing too many high-LCC simulations at low-LTS. Further effort is required to accurately simulate the smooth transition, possibly by focusing on the representation of prognostic subgrid variability of temperature and moisture. MERRA2 clouds are shown to reproduce the general dependence of low cloud cover to LTS but at the same time cover too little area. While the JPL EDMF is able to reproduce the low-level cloud cover, it simulates liquid water paths that are too low compared to MODIS and AMSR-E observations. On the other hand, the JPL EDMF average rain rate matches the observed dependence on LTS closely. It is interesting to note that the MERRA2 exhibits the "too few too bright" phenomenon, as its TOA albedo closely matches observations when LTS is below $20 \mathrm{~K}$ but the LCC is biased low and LWP has a strong negative correlation with LTS, something not seen in observations or the JPL EDMF results.

When investigating the effects of parameterized plume lateral entrainment and cloud top mixing physics, plume lateral entrainment rate was shown to mosteffectively control MBL cloud cover in relatively lowLTS regimes. With plume lateral entrainment set too high in these conditions, plumes are unable to mix moist surface air above the relatively weak inversion to the free troposphere, resulting in shallow stratocumulus layers instead of broken shallow cumuli. However, if plume lateral entrainment is too low, convection is too vigorous and too few stratiform clouds remain.

On the other hand, turbulent mixing at the boundary layer top was shown to have the greatest effect on MBL cloud cover in high-LTS regimes. Here, too much cloudtop turbulent mixing causes heating below the inversion level, resulting in the cloud layer drying out. Too little mixing, however, results in mixing lengths that are unphysically short in the stable lower troposphere just 
above the inversion layer. Both plume lateral entrainment and turbulent mixing play important roles between the LTS extremes where stratocumulus transitions into cumulus-dominated boundary layers.

Acknowledgments. The research described in this paper was carried out at the Jet Propulsion Laboratory, California Institute of Technology, under contract with the National Aeronautics and Space Administration. Parts of this research were supported by the U.S. Department of Energy, Office of Biological and Environmental Research, Earth System Modeling; the NASA MAP Program; the Office of Naval Research, Marine Meteorology Program, and the NOAA/CPO MAPP Program. The authors thank the editor and reviewers for their careful efforts in improving this manuscript. This work was supported by NASA CloudSat/CALIPSO science team funding to JPL under RTOP/WBS (105357/967701.02.01.02.08). CloudSat/CALIPSO 2B-GEOPRO-LIDAR and MODIS data are available from the CloudSat Data Repository at http://www.cloudsat.cira.colostate.edu/. The CCCM data are available at https://ceres.larc.nasa.gov/products.php? product $=$ CCCM. MERRA 2 product descriptions are available from https://disc.sci.gsfc.nasa.gov/datasets? page $=1 \&$ keywords $=$ MERRA- 2 and files are available from https://gmao.gsfc.nasa.gov/reanalysis/MERRA-2/ data_access/.

\section{APPENDIX A}

\section{Formulation of Lateral Entrainment Rate for Convective Updrafts and Mixing Length for Eddy- Diffusivity Part of the JPL EDMF Parameterization}

Although the JPL EDMF is detailed in Sušelj et al. (2013, 2019), we here summarize the mass-flux and eddy-diffusivity portions of the parameterization and describe differences between the Sušelj et al. (2019) parameterization and the one employed here. Convective plumes are modeled with 10 steady-state updrafts whose properties are governed by the following equations:

$$
\frac{\partial \varphi_{i}}{\partial z}=\varepsilon_{i}\left(\bar{\varphi}-\varphi_{i}\right)
$$

and

$$
\frac{1}{2} \frac{\partial w_{i}^{2}}{\partial z}=a_{w} B_{i}-b_{w} \varepsilon_{i} w_{i}^{2}
$$

where $\varphi$ represents moist conserved variables and horizontal momentum, $w$ is the updraft vertical velocity, and $B$ is the updraft buoyancy; $a_{w}=1$ and $b_{w}=1.5$ are constants; and $\varepsilon$ represent lateral entrainment rate for the updrafts. The subscript $i$ refers to one of the 10 individual updrafts and the overline represents a gridmean value. The lateral entrainment rate is parameterized assuming that lateral entrainment events occur as stochastic processes with a frequency given by a Poisson distribution function, following Romps and Kuang (2010). The probability of a lateral entrainment event occurrence depends on the height increment $(d z)$ that the updraft has risen. For the updraft traveling over the finite height $\Delta z$ (which is the depth of the model layer) the number of updraft events follows a Poisson distribution (Sušelj et al. 2019), producing a mean plume lateral entrainment rate:

$$
\varepsilon_{i}(\Delta z)=\frac{\varepsilon_{0}}{\Delta z} P\left(\frac{\Delta z}{L_{\varepsilon}}\right) .
$$

Here, $\varepsilon_{i}(\Delta z)$ represent the mean lateral entrainment rate over vertical distance $\Delta z, \varepsilon_{0}$ is the ratio of entrained mass-flux to the vertical mass-flux in the updraft (0.2), $L_{\varepsilon}$ the height that the updraft needs to travel to entrain once on average, and $P(\lambda)$ is the random number from the Poisson distribution with parameter $\lambda$. Here the formulation of $L_{\varepsilon}$ differs from Sušelj et al. (2019) as it also depends on the depth of the cloud layer:

$$
L_{\varepsilon}=\frac{w_{*}}{w_{o}^{2}} \max \left(z_{t}, z_{\min }\right)^{2},
$$

where $w_{*}$ is the Deardorff convective velocity scale, $z_{\min }=10 \mathrm{~m}$, and $z_{t}$ is the depth of the convective layer (estimated as the height of the deepest updraft from the previous time step). The parameter $w_{0}$ is a tunable factor used in section 5 to test the model's sensitivity of simulated cloudiness to plume lateral entrainment. The default value of this parameter is $126 \mathrm{~m} \mathrm{~s}^{-1 / 2}$.

The eddy-diffusivity portion of the parameterization is based on the prognostic TKE closure (Sušelj et al. 2019), in which the eddy diffusivity coefficients for heat and momentum are expressed as

$$
K_{m}=l_{m} \sqrt{e}
$$

and

$$
K_{h}=l_{h} \sqrt{e},
$$

where $l_{m}$ and $l_{h}$ represent the eddy-diffusivity mixing lengths for momentum and heat, respectively; and $e$ represents the turbulent kinetic energy. The eddydiffusivity lengths are the length $l_{0}$ multiplied by a stability function (which is a function of Richardson 
number and is different for heat and momentum; see and

Sušelj et al. (2019) for details), where $l_{0}$ is defined as

$$
l_{0}=\tau \sqrt{e}+(k z-\tau \sqrt{e}) e^{-z / z_{00}}
$$

(Teixeira and Cheinet 2004). The mixing length $l_{0}$ is a combination of the surface length scale $(k z$, where $k=0.4$ is the von Kármán constant and $z$ is altitude) and the boundary layer length scale (which is expressed as a product of time scale $\tau$ and velocity scale $\sqrt{e}$ ). The parameter $z_{00}$ is the typical depth over which the surface length scale is not relevant $(100 \mathrm{~m})$. The time scale $\tau$ has a maximum value of $400 \mathrm{~s}$ and represents a combination of the time scale for a neutral atmosphere $\left(\tau_{0}\right)$ estimated as the highest plume height from the previous time step $\left(z_{d}\right)$ and the 3D surface wind scale and the time scale for a statically stable column where ( $N$ the Brunt-Väisälä frequency):

$$
\tau_{0}=\frac{z_{d}}{3 u_{*}}
$$

$$
\tau=\frac{\tau_{0} A_{s}}{N^{2}}
$$

The parameter $A_{s}$ is a tunable factor used in section 5 to test the model's sensitivity of simulated cloudiness to the magnitude of small-scale mixing. The default value for this parameter is $10^{-6} \mathrm{~s}^{-2}$. A minimum time scale of $1 \mathrm{~s}$ is imposed for $\tau_{0}$ and a maximum time scale of $400 \mathrm{~s}$ is imposed for $\tau$.

\section{APPENDIX B}

\section{Initial Conditions, Surface Fluxes, and Tendencies Provided by MERRA2}

This appendix lists in Table B1 the MERRA2 variables that are used to either initialize the model profiles (labeled with "I") or alter the model profiles through tendencies or time-varying surface fluxes (labeled with "V") or both (labeled with "IV").

\begin{tabular}{|c|c|c|c|}
\hline MERRA2 file identifier & MERRA2 variable name & MERRA2 variable description & Use \\
\hline inst3_3d_asm_Nv & $H$ & Midlayer heights & I \\
\hline inst3_3d_asm_Nv & DELP & Layer pressure thickness & I \\
\hline inst3_3d_asm_Nv & PL & Midlayer pressure & I \\
\hline tavg3_3d_nav_Ne & PLE & Layer edge pressure & I \\
\hline tavg3_3d_nav_Ne & ZLE & Layer edge heights & I \\
\hline inst3_3d_asm_Nv & QV & Specific humidity & I \\
\hline inst3_3d_asm_Nv & QL & Mass fraction of cloud liquid water & I \\
\hline inst3_3d_asm_Nv & QI & Mass fraction of cloud ice water & I \\
\hline inst3_3d_asm_Nv & $T$ & Air temperature & I \\
\hline inst1_2d_asm_Nx & QV10M & 10-m specific humidity & I \\
\hline inst1_2d_asm_Nx & $\mathrm{T} 10 \mathrm{M}$ & 10-m air temperature & I \\
\hline inst1_2d_asm_Nx & U10M & 10-m eastward wind & I \\
\hline inst1_2d_asm_Nx & V10M & 10-m northward wind & I \\
\hline inst3_3d_asm_Nv & $U$ & 3D eastward wind & IV \\
\hline inst3_3d_asm_Nv & $V$ & 3D northward wind & IV \\
\hline inst3_3d_asm_Nv & OMEGA & $3 \mathrm{D}$ vertical pressure velocity & IV \\
\hline tavg1_2d_flx_Nx & EFLUX & Surface total latent energy flux & IV \\
\hline tavg1_2d_flx_Nx & HFLUX & Surface sensible heat flux from turbulence & IV \\
\hline tavg1_2d_flx_Nx & USTAR & Surface velocity scale & IV \\
\hline tavg1_2d_flx_Nx & RHOA & Air density at surface & IV \\
\hline inst3_3d_aer_Nv & $\mathrm{SO} 4$ & Sulfate aerosol mixing ratio & IV \\
\hline inst3_3d_aer_Nv & SS001 & Sea salt mixing ratio (bin 001 ) & IV \\
\hline inst3_3d_aer_Nv & SS002 & Sea salt mixing ratio (bin 002 ) & IV \\
\hline inst3_3d_aer_Nv & SS003 & Sea salt mixing ratio (bin 003 ) & IV \\
\hline inst3_3d_aer_Nv & SS004 & Sea salt mixing ratio (bin 004) & IV \\
\hline inst3_3d_aer_Nv & SS005 & Sea salt mixing ratio (bin 005 ) & IV \\
\hline tavg3_3d_qdt_Np & DQVDTDYN & Tendency of specific humidity due to dynamics & $\mathrm{V}$ \\
\hline tavg3_3d_qdt_Np & DQIDTDYN & Tendency of ice water due to dynamics & V \\
\hline tavg3_3d_qdt_Np & DQLDTDYN & Tendency of liquid water due to dynamics & V \\
\hline tavg3_3d_tdt_Np & DTDTDYN & Tendency of air temperature due to dynamics & V \\
\hline inst1_2d_asm_Nx & PS & Surface pressure & V \\
\hline inst1_2d_asm_Nx & TS & Surface skin temperature & V \\
\hline
\end{tabular}

TABLE B1. Atmospheric and surface reanalyses from MERRA2 used as initial conditions and large-scale advective tendencies for the SCM. 


\section{REFERENCES}

Abdul-Razzak, H., and S. J. Ghan, 2000: A parameterization of aerosol activation: 2. Multiple aerosol types. J. Geophys. Res., 105, 6837-6844, https://doi.org/10.1029/1999JD901161.

Boucher, O., and Coauthors, 2013: Clouds and aerosols. Climate Change 2013: The Physical Science Basis, T. F. Stocker et al., Eds., Cambridge University Press, 571-658.

Cheinet, S., and J. Teixeira, 2003: A simple formulation for the eddy-diffusivity parameterization of cloud-topped boundary layers. Geophys. Res. Lett., 30, 1930, https://doi.org/10.1029/ 2003 GL017377.

de Roode, S. R., and Coauthors, 2016: Large-eddy simulations of EUCLIPSE-GASS Lagrangian stratocumulus-to-cumulus transitions: Mean state, turbulence, and decoupling. J. Atmos. Sci., 73, 2485-2508, https://doi.org/10.1175/JAS-D-15-0215.1.

Efron, B., 1979: Bootstrap methods: Another look at the jackknife. Ann. Stat., 7, 1-26, https://doi.org/10.1214/aos/1176344552.

Gelaro, R., and Coauthors, 2017: The Modern-Era Retrospective Analysis for Research and Applications, version 2 (MERRA-2). J. Climate, 30, 5419-5454, https://doi.org/10.1175/ JCLI-D-16-0758.1.

Golaz, J. C., V. E. Larson, and W. R. Cotton, 2002: A PDF-based model for boundary layer clouds. Part I: Method and model description. J. Atmos. Sci., 59, 3540-3551, https://doi.org/ 10.1175/1520-0469(2002)059<3540:APBMFB >2.0.CO;2.

Grabowski, W. W., 1998: Toward cloud resolving modeling of largescale tropical circulations: A simple cloud microphysics parameterization. J. Atmos. Sci., 55, 3283-3298, https://doi.org/10.1175/ 1520-0469(1998)055<3283:TCRMOL > 2.0.CO;2.

Greenwald, T. J., R. Bennartz, M. Lebsock, and J. Teixeira, 2018: An uncertainty data set for passive microwave satellite observations of warm cloud liquid water path. J. Geophys. Res., 123, 3668-3687, https://doi.org/10.1002/2017JD027638.

Griffin, B. M., and V. E. Larson, 2016: A new subgrid-scale representation of hydrometeor fields using a multivariate PDF. Geosci. Model Dev., 9, 2031-2053, https://doi.org/10.5194/ gmd-9-2031-2016.

Gustafson, W. I., A. M. Vogelmann, X. Cheng, S. Endo, B. Krishna, Z. Li, T. Toto, and H. Xiao, 2017: Recommendation for the implementation of the LASSO workflow. DOE Atmospheric radiation Measurement Climate Research Facility. Tech. Doc. DOE/SC-ARM-17-031, https://doi.org/10.2172/1406259.

Huang, H. Y., A. Hall, and J. Teixeira, 2013: Evaluation of the WRF PBL parameterizations for marine boundary layer clouds: Cumulus and stratocumulus. Mon. Wea. Rev., 141, 2265-2271, https://doi.org/10.1175/MWR-D-12-00292.1.

Iacono, M. J., E. J. Mlawer, S. A. Clough, and J. J. Morcrette, 2000: Impact of an improved longwave radiation model, RRTM, on the energy budget and thermodynamic properties of the NCAR community climate model, CCM3. Geophys. Res. Lett., 105, 14 873-14 890, https://doi.org/10.1029/2000JD900091.

Jakob, C., 2003: An Improved strategy for the evaluation of cloud parameterizations in GCMs. Bull. Amer. Meteor. Soc., 84, 1387-1401, https://doi.org/10.1175/BAMS-84-10-1387.

Kalmus, P., M. Lebsock, and J. Teixeira, 2014: Observational boundary layer energy and water budgets of the stratocumulusto-cumulus transition. J. Climate, 27, 9155-9170, https://doi.org/ 10.1175/JCLI-D-14-00242.1.

Karlsson, J., G. Svensson, and H. Rodhe, 2008: Cloud radiative forcing of subtropical low level clouds in global models. Climate Dyn., 30, 779-788, https://doi.org/10.1007/s00382007-0322-1.
Kato, S., S. Sun-Mack, W. F. Miller, F.G. Rose, Y. Chen, P. Minnis, and B. A. Wielicki, 2010: Relationships among cloud occurrence frequency, overlap, and effective thickness derived from CALIPSO and CloudSat merged cloud vertical profiles. J. Geophys. Res., 115, D00H28, https://doi.org/10.1029/ 2009JD012277.

—_ and Coauthors, 2011: Improvements of top-of-atmosphere and surface irradiance computations with CALIPSO-, CloudSat-, and MODIS-derived cloud and aerosol properties. J. Geophys. Res., 116, D19209, https://doi.org/10.1029/ 2011JD016050.

Khairoutdinov, M., and Y. Kogan, 2000: A new cloud physics parameterization in a large-eddy simulation model of marine stratocumulus. Mon. Wea. Rev., 128, 229-243, https://doi.org/ 10.1175/1520-0493(2000)128<0229:ANCPPI > 2.0.CO;2.

Klein, S., and D. L. Hartmann, 1993: The seasonal cycle of low stratiform clouds. J. Climate, 6, 1587-1606, https://doi.org/ 10.1175/1520-0442(1993)006<1587:TSCOLS $>2.0$. CO;2.

Kubar, T. L., G. L. Stephens, M. Lebsock, V. E. Larson, and P. A. Bogenschutz, 2015: Regional assessments of low clouds against large-scale stability in CAM5 and CAM-CLUBB using MODIS and ERA-Interim reanalysis data. J. Climate, 28, 1685-1706, https://doi.org/10.1175/JCLI-D-14-00184.1.

L'Ecuyer, T., and G. Stephens, 2002: An estimation-based precipitation retrieval algorithm for attenuating radars. J. Appl. Meteor. Climatol., 41, 272-285, https://doi.org/10.1175/15200450(2002)041<0272:AEBPRA $>2.0$.CO;2.

Lebsock, M., and T. S. L'Ecuyer, 2011: The retrieval of warm rain from CloudSat. J. Geophys. Res., 116, D20209, https://doi.org/ 10.1029/2011JD016076.

- and H. Su, 2014: Application of active spaceborne remote sensing for understanding biases between passive cloud water path retrievals. J. Geophys. Res. Atmos., 119, 8962-8979, https://doi.org/10.1002/2014JD021568.

Lock, A. P., A. R. Brown, M. R. Bush, G. M. Martin, and R. N. B. Smith, 2000: A new boundary layer mixing scheme. Part I: Scheme description and single-column model tests. Mon. Wea. Rev., 128, 3187-3199, https://doi.org/10.1175/1520-0493(2000) $128<3187$ :ANBLMS $>2.0$. CO;2.

Mace, G. G., and Q. Zhang, 2014: The CloudSat radar-lidar geometrical profile product (RL-GeoProf): Updates, improvements, and selected results. J. Geophys. Res. Atmos., 119, 9441-9462, https://doi.org/10.1002/2013JD021374.

Marchand, R., G. G. Mace, T. Ackerman, and G. Stephens, 2008: Hydrometeor detection using CloudSat-An Earth-orbiting 94-GHz cloud radar. J. Atmos. Oceanic Technol., 25, 519-533, https://doi.org/10.1175/2007JTECHA1006.1.

Morrison, H., and A. Gettelman, 2008: A new two-moment bulk stratiform cloud microphysics scheme in the Community Atmosphere Model, version 3 (CAM3). Part I: Description and numerical tests. J. Climate, 21, 3642-3659, https://doi.org/ 10.1175/2008JCLI2105.1.

Nam, C., S. Bony, J. L. Dufresne, and H. Chepfer, 2012: The too few, too bright tropical low-cloud problem in CMIP5 models. Geophys. Res. Lett., 39, L21801, https://doi.org/10.1029/ 2012GL053421.

Neggers, R. A. J., A. P. Siebesma, and T. Heus, 2012: Continuous single-column model evaluation at a permanent meteorological supersite. Bull. Amer. Meteor. Soc., 93, 1389-1400, https:// doi.org/10.1175/BAMS-D-11-00162.1.

Nuijens, L., and B. Stevens, 2012: The influence of wind speed on shallow marine cumulus convection. J. Atmos. Sci., 69, 168184, https://doi.org/10.1175/JAS-D-11-02.1. 
Pincus, R., H. W. Barker, and J.-J. Morcrette, 2003: A fast, flexible, approximate technique for computing radiative transfer in inhomogeneous cloud fields. J. Geophys. Res., 108, 4376, https://doi.org/10.1029/2002JD003322.

Platnick, S., and Coauthors, 2017: The MODIS cloud optical and microphysical products: collection 6 updates and examples from Terra and Aqua. IEEE Trans. Geosci. Remote Sens., 55, 502-525, https://doi.org/10.1109/TGRS.2016.2610522.

Rapp, A. D., M. Lebsock, and T. S. L'Ecuyer, 2013: Low cloud precipitation climatology in the southeastern Pacific marine stratocumulus region using CloudSat. Environ. Res. Lett., 8, 014027, https://doi.org/10.1088/1748-9326/8/1/014027.

Romps, D. M., and Z. Kuang, 2010: Nature versus nurture in shallow convection. J. Atmos. Sci., 67, 1655-1666, https:// doi.org/10.1175/2009JAS3307.1.

Sandu, I., and B. Stevens, 2011: On the factors modulating the stratocumulus to cumulus transitions. J. Atmos. Sci., 68, 18651881, https://doi.org/10.1175/2011JAS3614.1.

,-- , and R. Pincus, 2010: On the transitions in marine boundary layer cloudiness. Atmos. Chem. Phys., 10, 23 58923 622, https://doi.org/10.5194/acp-10-2377-2010.

Siebesma, A. P., and J. Teixeira, 2000: An advection-diffusion scheme for the convective boundary layer: Description and 1D results. 14th Symp. on Boundary Layer and Turbulence, Aspen, CO, Amer. Meteor. Soc., 4.16, https://ams.confex.com/ ams/AugAspen/techprogram/paper_14840.htm.

— P. M. M. Soares, and J. Teixeira, 2007: A combined eddydiffusivity mass-flux approach for the convective boundary layer. J. Atmos. Sci., 64, 1230-1248, https://doi.org/10.1175/JAS3888.1.

Stephens, G., D. Winker, J. Pelon, C. Trepte, D. Vane, C. Yuhas, T. L'Ecuyer, and M. Lebsock, 2018: CloudSat and CALIPSO within the A-Train: Ten years of actively observing the earth system. Bull. Amer. Meteor. Soc., 99, 569-581, https://doi.org/ 10.1175/BAMS-D-16-0324.1.

Sušelj, K., J. Teixeira, and G. Matheou, 2012: Eddy diffusivity/mass flux and shallow cumulus boundary layer: An updraft PDF multiple mass flux scheme. J. Atmos. Sci., 69, 1513-1533, https://doi.org/10.1175/JAS-D-11-090.1.

- — - , and D. Chung, 2013: A unified model for moist convective boundary layers based on a stochastic eddydiffusivity/mass-flux parameterization. J. Atmos. Sci., 70, 1929-1953, https://doi.org/10.1175/JAS-D-12-0106.1.
—_, T. F. Hogan, and J. Teixeira, 2014: Implementation of a stochastic eddy-diffusivity/mass-flux parameterization into the Navy Global Environmental Model. Wea. Forecasting, 29, 1374-1390, https://doi.org/10.1175/WAF-D14-00043.1.

_- M. Kurowski, and J. Teixeira, 2019: On the factors controlling the development of shallow convection in eddy-diffusivity/ mass-flux models. J. Atmos. Sci., 76, 433-456, https://doi.org/ 10.1175/JAS-D-18-0121.1.

Teixeira, J., and Coauthors, 2011: Tropical and subtropical cloud transitions in weather and climate prediction models: The GCSS/WGNE Pacific Cross-Section Intercomparison (GPCI). J. Climate, 24, 5223-5256, https://doi.org/10.1175/ 2011JCLI3672.1.

— the eddy-diffusivity parameterization of dry convection. Bound.-Layer Meteor., 110, 435-453, https://doi.org/10.1023/ B:BOUN.0000007230.96303.0d.

Wentz, F. J., T. Meissner, C. Gentemann, and M. Brewer, 2014: Remote sensing systems Aqua ASMR-E daily environmental suite on $0.25^{\circ}$ grid, version 7.0. Remote Sensing Systems, Santa Rosa, CA, accessed 1 August 2019, http://www.remss.com/ missions/amsr.

Wielicki, B. A., B. R. Barkstrom, E. F. Harrison, R. B. Lee III, G. L. Smith, and J. E. Cooper, 1996: Clouds and the Earth's Radiant Energy System (CERES): An Earth Observing System Experiment. Bull. Amer. Meteor. Soc., 77, 853-868, https://doi.org/10.1175/1520-0477(1996)077<0853:CATERE> 2.0.CO;2.

Wood, R., 2012: Stratocumulus clouds. Mon. Wea. Rev., 140, 2373 2423, https://doi.org/10.1175/MWR-D-11-00121.1.

—_, and C. S. Bretherton, 2006: On the relationship between stratiform low cloud cover and lower-tropospheric stability. J. Climate, 19, 6425-6432, https://doi.org/10.1175/ JCLI3988.1.

— , and Coauthors, 2015: Clouds, aerosols, and precipitation in the marine boundary layer: An ARM mobile facility deployment. Bull. Amer. Meteor. Soc., 96, 419-440, https://doi.org/10.1175/ BAMS-D-13-00180.1.

Yamaguchi, T., G. Feingold, and J. Kazil, 2017: Stratocumulus to cumulus transition by drizzle. J. Adv. Model. Earth Syst., 9, 2333-2349, https://doi.org/10.1002/2017MS001104. 